\title{
The Catechol-O-Methyltransferase Polymorphism: Relations to the Tonic-Phasic Dopamine Hypothesis and Neuropsychiatric Phenotypes
}

\author{
Robert M Bilder, ${ }^{*,}$, Jan Volavka ${ }^{2,3}$, Herbert M Lachman ${ }^{4}$ and Anthony A Grace ${ }^{5}$ \\ 'Departments of Psychiatry and Biobehavioral Sciences, David Geffen School of Medicine and Psychology, UCLA Neuropsychiatric Institute, \\ University of California at Los Angeles, Los Angeles, CA, USA; ${ }^{2}$ Nathan Kline Institute for Psychiatric Research, Orangeburg, NY, USA; ${ }^{3}$ New York \\ University School of Medicine, New York, NY, USA; ${ }^{4}$ Albert Einstein College of Medicine, Bronx, NY, USA; ${ }^{5}$ Departments of Neuroscience, \\ Psychiatry, and Psychology, University of Pittsburgh, Pittsburgh, PA, USA
}

\begin{abstract}
Diverse phenotypic associations with the catechol-O-methyltransferase (COMT) Val ${ }^{58}$ Met polymorphism have been reported. We suggest that some of the complex effects of this polymorphism be understood from the perspective of the tonic-phasic dopamine (DA) hypothesis. We hypothesize that the COMT Met allele (associated with low enzyme activity) results in increased levels of tonic DA and reciprocal reductions in phasic DA in subcortical regions and increased DI transmission cortically. This pattern of effects is hypothesized to yield increased stability but decreased flexibility of neural network activation states that underlie important aspects of working memory and executive functions; these effects may be beneficial or detrimental depending on the phenotype, a range of endogenous factors, and environmental exigencies. The literature on phenotypic associations of the COMT Val ${ }^{158}$ Met polymorphism is reviewed, highlighting areas where this hypothesis may have explanatory value, and pointing to possible directions for refinement of relevant phenotypes and experimental evaluation of this hypothesis.

Neuropsychopharmacology (2004) 29, 1943-1961, advance online publication, II August 2004; doi: I0.1038/sj.npp. I 300542
\end{abstract}

Keywords: COMT; cognition; schizophrenia; bipolar disorder; alcoholism; aggression; obsessive-compulsive disorder; dopamine

\section{INTRODUCTION}

Alterations in catecholamine metabolism have been invoked in hypotheses to explain most severe neuropsychiatric syndromes. The major enzymes responsible for catecholamine catabolism, catechol-O-methyltransferase (COMT) and monoamine oxidase (MAO), have received corresponding attention, including the development of therapies that target these enzymes. Considerable excitement has surrounded the identification of a common biallelic singlenucleotide polymorphism, involving a Met $\rightarrow$ Val substitution at codon 158 of the COMT gene (Lachman et al, 1996), which has been localized to chromosome 22q11.1-q11.2. The methionine (Met) allele at this locus is associated with

*Correspondence: Dr RM Bilder, Departments of Psychiatry and Biobehavioral Sciences, David Geffen School of Medicine and Psychology, UCLA Neuropsychiatric Institute C8-849, University of California at Los Angeles, 760 Westwood Plaza, Los Angeles, CA 90095, USA, Tel: + I 310825 9474; Fax: + I 310825 2850;

E-mail: rbilder@mednet.ucla.edu

Received 26 November 2003; revised 7 July 2004; accepted 19 July 2004

Online publication: 7 July 2004 at http://www.acnp.org/citations/ Npp07200403547/default.pdf low enzymatic activity, whereas the valine ( Val) allele is associated with high activity. Homozygosity for the Met allele yields a three- to four-fold reduction in COMT activity relative to Val homozygotes, with heterozygotes demonstrating intermediate activity (Weinshilboum, et al, 1999). The frequency of the low-activity (Met) allele in diverse populations has ranged from 0.01 to 0.62 (Palmatier et al, 1999). The relatively high frequency of this polymorphism, together with its functional role in catecholamine metabolism, rapidly led to multiple efforts to determine its possible relevance to a range of neuropsychiatric phenotypes.

Among the reported neurobehavioral associations with the COMT $\mathrm{Val}^{158} \mathrm{Met}$ polymorphism, some findings appear at least superficially inconsistent, raising questions about both phenotype definitions and the mechanisms by which this polymorphism exerts its effects. For example, the Met allele has been associated with increased aggression, and more severe treatment-refractory symptoms in schizophrenia, and also with 'better' prefrontal cortex (PFC) function in both healthy people and those with schizophrenia. These findings are difficult to reconcile with evidence that aggression and negative symptoms have been linked to impaired prefrontal function. We argue below that viewing the COMT $\mathrm{Val}^{158}$ Met polymorphism from the 
perspective of the tonic-phasic dopamine (DA) hypothesis may help resolve some of these apparent inconsistencies, and more clearly frame experiments designed to refine relevant phenotypes that consider the heterogeneity of frontal lobe systems and the multiple roles played by DA in these systems. We first outline the hypothesis on theoretical grounds, then summarize how the hypothesis relates to the existing literature, and finally point to some directions for future research.

\section{THEORETICAL BACKGROUND AND HYPOTHESIS}

The prevailing hypothesis about the functional role of COMT is that it is important in the modulation of prefrontal DA (DA) systems, and that the high-activity form of COMT (associated with the Val allele) leads to cortical hypodopaminergia, increasing the risk for schizophrenia and other deficits in executive and working memory functions attributed to PFC (Egan et al, 2001). This hypothesis is a useful starting point but may offer only a partial account, since it does not consider the distinctive roles played by tonic and phasic DA in the regulation of cortical and subcortical systems that are important in the expression of multiple neuropsychiatric phenotypes.

Both pharmacological and genetic manipulations of COMT (Gogos et al, 1998) have clarified its role in DA metabolism in rodents. Under basal physiological circumstances both COMT inhibition and genetic deficiencies of COMT have little effect on DA concentrations in the striatum, where the DA transporter (DAT) and MAO offer efficient routes for elimination, but the lack of COMT does markedly increase levels of DOPAC, and decreases HVA to undetectable levels (Huotari et al, 2002). In contrast, DA concentrations were increased in the frontal cortex especially of male animals deficient in COMT (Gogos et al, 1998). With levodopa administration, there are more marked effects, with increases in DOPAC, DHPG, and DA in the striatum, and accumulation of L-DOPA, which appears particularly important in the cortex and hypothalamus (Huotari et al, 2002). As will be noted in more detail below, there were also behavioral and 'emotional' changes in the COMT knockout rodents, and some of these effects were sexually dimorphic (Gogos et al, 1998). The findings from these studies in rodents provide insights but may be difficult to extrapolate to humans. For example, HVA concentrations in the human striatum are more than 10 times greater than in rodents, suggesting that COMT may be particularly important in primates (Huotari et al, 2002; Kopin, 1985).

While a broad view of the COMT Val ${ }^{158}$ Met polymorphism should consider possible effects on other neurotransmitter systems, particularly norepinephrine, and regions other than the PFC (Bilder et al, 2002), the following arguments focus selectively on distinctions within the DA system. It should also be pointed out that while substantial research on the COMT $\mathrm{Val}^{158} \mathrm{Met}$ polymorphism has examined its relations with the diagnosis of schizophrenia, or its effects on cognitive performance within schizophrenia samples, we believe that the phenotypic expression of this polymorphism is more general and affects both a broad range of neuropsychiatric syndromes and normal behavior.
The key elements of this hypothesis about the possible role of COMT in DA systems come from basic physiological studies, neural network simulations (including detailed biophysical models), and cognitive models. We highlight below each of the elements of this hypothesis and how these different levels of description relate to each other.

\section{COMT Val ${ }^{158}$ MET Polymorphism and Tonic-Phasic DA}

We hypothesize that the functional effects of the COMT polymorphism on DA neurotransmission may be better understood from the perspective of the theory differentiating the roles of tonic and phasic DA (Grace, 1991). The dichotomy between tonic and phasic DA systems has received considerable empirical support and helped resolve multiple inconsistencies with regard to the effects of lesions to dopaminergic systems and the effects of treatments with dopaminergic agonists and antagonists (Grace, 1991, 1993; Moore et al, 1999). In brief, this theory states that the dynamics of DA regulation within limbic striatal regions occurs via two processes: (1) a high-amplitude transient, phasic DA release mediated by DA neuron burst firing, and (2) constant low-level 'background' tonic DA that is regulated by baseline DA neuron firing and corticostriatal glutamatergic afferents. Activation of burst firing in DA neurons in response to behaviorally relevant stimuli trigger the phasic component of DA release on to postsynaptic targets. In contrast, tonic DA levels are proposed to regulate the amplitude of the phasic DA response via stimulation of highly sensitive DA terminal autoreceptors. In this way, low tonic DA release would set the responsivity of the DA system to behaviorally activating stimuli. Summaries of the tonic-phasic DA hypothesis are published elsewhere (Floresco et al, 2003; Grace, 1991).

The possible functions of COMT in tonic-phasic DA regulation can be narrowed by considering its role relative to other mechanisms for DA catabolism and removal from synaptic and extrasynaptic spaces. According to the tonic/ phasic model, high-amplitude phasic DA released by behaviorally driven bursts of action potentials within subcortical systems is regulated by fast reuptake via the DAT (Floresco et al, 2003; Grace, 1991, 1993; Moore et al, 1999). This phasic component would not be affected directly by COMT, given that COMT is not present in DA terminals, and is thought to serve its role principally in the catabolism of extraneuronal DA in glial cells and/or postsynaptic neurons (Gogos et al, 1998). These observations suggest that COMT plays a larger role in modulation of DA once it has escaped the synaptic cleft (Floresco et al, 2004).

Within subcortical systems, this distinction is important, in that low levels of DA that are not subject to the fast reuptake process will escape the synaptic cleft and contribute to the tonic, extracellular pool of DA (Floresco et al, 2003). Increases in tonic DA serve to suppress phasic DA activity via action on autoreceptors on the DA terminal. Thus, higher activity of COMT associated with the Val allele would cause a selective decrease in tonic DA subcortically, thereby producing an activation of phasic DA transmission, while the lower activity form of COMT associated with the Met allele would increase tonic DA and decrease phasic DA subcortically. 
In contrast, $\mathrm{DA}$ transmission in the PFC appears to be under different regulatory dynamics. There are substantially fewer DATs on DA terminals in the PFC (Lewis et al, 2001; Sesack et al, 1998), which probably underlies the relatively higher proportion of DA in the extracellular space in the PFC compared to the striatum (Moghaddam et al, 1993; Sharp et al, 1986). Indeed, it is proposed that most DA in the PFC is removed via reuptake into noradrenergic terminals (Gresch et al, 1995; Yamamoto and Novotney, 1998), which requires DA to diffuse long distances before inactivation via this route. As a result, DA in the PFC would be capable of exerting effects at greater diffusional distances, acting on D1 receptors located at extrasynaptic sites (Smiley et al, 1994). Therefore, by metabolizing DA that has diffused away, the actions of COMT would be expected to have a more substantial impact on DA transmission, in general, within the PFC and to exert a greater relative effect on D1 receptors. In the PFC, we would thus expect the Val allele to decrease overall DA concentrations, whereas the Met allele would result in increased DA concentrations.

To the extent that COMT serves to modulate the balance of tonic and phasic DA function subcortically, and overall DA transmission cortically, the effect of the Met allele would be to increase tonic DA levels and decrease phasic DA release in subcortical regions, and increase DA concentrations in cortex, thereby enhancing the functions associated with tonic DA system activity and D1 stimulation cortically. In contrast, the Val allele would be expected to have complementary effects, increasing phasic DA transmission and D2 stimulation subcortically, while decreasing tonic DA neurotransmission subcortically and decreasing overall DA concentrations in the PFC, thereby reducing cortical D1 neurotransmission. These functional dynamics are outlined schematically in Figures 1 and 2.

\section{Relations to Physiological, Neural Network, and Neurocognitive Models}

A variety of additional knowledge helps bridge the gap between the cellular-molecular mechanisms outlined above and the activity of larger populations of neurons that can ultimately be related to behavioral functions. Our hypothesis is based, in part, on observations that pyramidal cells of the dorsolateral PFC, together with their striatal projection targets, participate critically in the sustained activity of the neural networks in which they are embedded (Goldman-Rakic, 1995a, b, 1998). In agreement with many of our colleagues, we hypothesize that these sustained activation states depend heavily on the PFC pyramidal neuron responses to D1 receptor stimulation and tonic DA transmission in the striatum. We refer to these effects of D1 and tonic DA transmission as underlying the stability of cortical activation states, and intend this to be interpreted in terms of the neural networks whose sustained activity is promoted by this kind of DA transmission. In contrast, and also in accord with multiple sources, we hypothesize that phasic DA (primarily via D2 receptor function) performs a complementary role by enhancing the plasticity of these activation states, serving to inhibit the sustained activity of these neural networks and enabling transitions to different activation states.
Tonic/Phasic DA Transmission - nucleus accumbens:

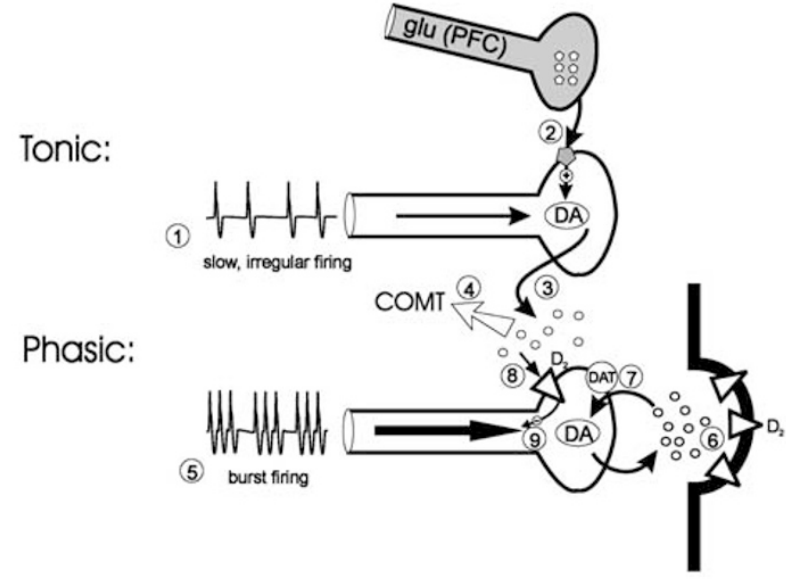

DA Transmission - PFC:

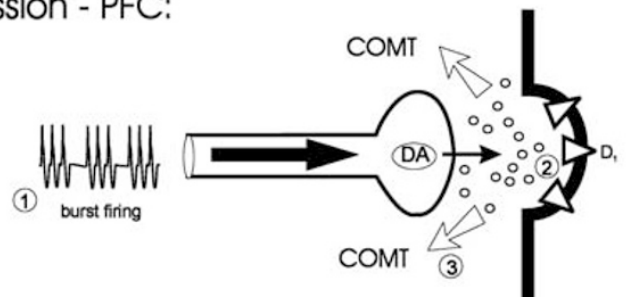

Figure I Tonic-phasic regulation of DA transmission in the nucleus accumbens and PFC. (Top) In the nucleus accumbens, the constant low level of extracellular DA is termed tonic DA. Tonic DA release is dependent on slow, irregular spike activity of VTA DA neurons $(I)$ and is proposed to be modulated by glutamatergic afferents, such as those from the PFC (2). This results in the release (possibly from extrasynaptic sites of the DA terminal) of low levels of DA (on the order of 5-20 nM) into the extrasynaptic space (3), where it is subject to metabolism by COMT (4). In contrast, the phasic DA transmission is proposed to mediate behaviorally salient stimuli, such as those associated with reward. This transmission is triggered by burst firing of VTA neurons (5), which release very high levels of DA into the synaptic cleft (on the order of $\mu \mathrm{M}$ concentrations), where it stimulates postsynaptic D2 receptors (6). Phasic DA is inactivated by removal from the synaptic cleft via rapid uptake by the DAT (DAT, 7) before it can escape the synaptic cleft; therefore, phasic DA is not subject to metabolism by the extracellularly located enzyme COMT. Although tonic DA is in far too low a concentration to stimulate intrasynaptic D2 receptors, it is of sufficient magnitude to stimulate presynaptic D2 autoreceptors located on the DA terminal (8), which will then inhibit phasic DA release (9). Therefore, tonic DA levels are controlled by an interaction of glutamatergic presynaptic stimulation and COMT metabolism; tonic DA in the extrasynaptic space in turn will downregulate phasic DA release. (Bottom) In contrast, the regulation of DA transmission in the PFC is markedly different. Burst firing of VTA DA neurons (I) releases high concentrations of DA into the synaptic cleft (2). However, it is known that mesocortical DA neurons do not contain high levels of DAT; therefore, unlike the mesoaccumbens system, phasic DA transmission in the PFC is not restricted to the synaptic cleft. Instead, DA is free to diffuse out of the synaptic cleft to stimulate nearby postsynaptic sites. Thus, in the PFC, COMT plays a much more important role in the inactivation of DA following its release.

This fundamental complementarity of tonic and phasic DA transmission and reciprocity of D2 and D1 receptor stimulation is supported by detailed cellular studies and biophysical modeling. For example, DA generally produces a biphasic response in prefrontal pyramidal cells: D2/D4 stimulation produces an excitation of inhibitory interneurons, thereby inhibiting pyramidal neurons (Gorelova et al, 


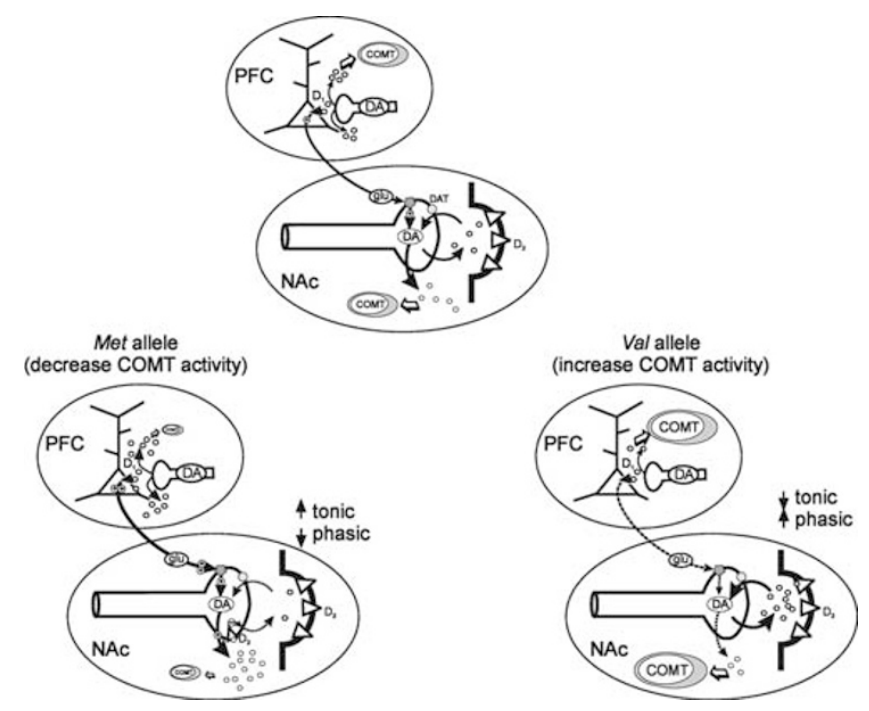

Figure 2 Activity of COMT differentially affects DA transmission in the PFC and the nucleus accumbens. (Top center) DA released from DA terminals in the PFC stimulates postsynaptic DI receptors on pyramidal neurons, where it exerts an excitatory effect on neuronal firing. The ability of DA to stimulate multiple PFC neurons is limited by the ability of COMT to metabolize DA. Increased activity in PFC pyramidal neurons will increase glutamate release within the nucleus accumbens, where it can stimulate presynaptic receptors on DA terminals to lead to tonic DA release. Tonic DA will stimulate autoreceptors on DA terminals to decrease phasic DA release; the level of tonic DA is regulated in the extrasynaptic space via the actions of COMT. (Bottom left) The presence of the Met allele in COMT will decrease its overall activity. This will result in less metabolism of DA in the PFC, and greater stimulation of PFC pyramidal neuron firing and PFCaccumbens glutamate transmission. As a consequence, there will be increased glutamate-stimulated tonic DA release in the nucleus accumbens. When combined with the decreased metabolism of tonic DA by COMT in the accumbens, the result is high levels of tonic DA and potent suppression of the phasic DA response. (Bottom, right) In contrast, the presence of the Val allele in COMT will increase its activity and produce a markedly different constellation of events. High COMT activity in the PFC will increase DA metabolism in this area, thereby limiting the DI-mediated excitation of PFC pyramidal neurons. This will diminish glutamatestimulated tonic DA release in the accumbens, which will be exacerbated by increased tonic DA metabolism by COMT. The consequence will be a release of phasic DA transmission from tonic DA modulation, resulting in abnormally high phasic DA response.

2002); in contrast, D1 stimulation facilitates and prolongs the 'up' state in the pyramidal neurons (Lewis and O'Donnell, 2000). In addition, D1 stimulation may also enhance GABAergic transmission. Thus, it has been proposed that $\mathrm{D} 1$ neurotransmission may be mediated by enhancements of persistent $\mathrm{Na}(+)$ and $\mathrm{N}$-methyl-D-aspartate (NMDA) conductances or decreases in AMPA conductances, along with increases in $\operatorname{GABA}(\mathrm{A})$ conductances (Durstewitz et al, 2000b).

Detailed biophysical models of PFC neuronal architecture support the validity of the proposed complementary roles of tonic and phasic DA in neuronal ensembles (Brunel and Wang, 2001; Durstewitz et al, 1999, 2000a, b). Durstewitz and co-workers suggest that tonic, sustained D1 activation helps establish and maintain stability of neural networks by preventing 'uncontrolled, spontaneous switches into highactivity states (ie spontaneous activation of task-irrelevant representations)' (Durstewitz et al, 2000b). Durstewitz and co-workers further highlight the importance of tonic D1 neurotransmission in sustaining higher concentrations of extrasynaptic DA within PFC over relatively long periods. They see this effect as ideally suited to facilitating the persistence of network activation states and assuring their freedom from perturbation by 'noisy' inputs; according to this model, tonic D1 stimulation increases the thresholds that must be crossed to switch from one high-activity state to another, while at the same time facilitating the maintenance of the high-activity state once it is achieved. Thus, the overall network system will tend to remain in a particular state unless it receives substantial additional inputs (Durstewitz and Seamans, 2002).

In contrast, the effects of D2 stimulation and phasic DA release from burst firing is known to occur more transiently (on a time scale of hundreds of milliseconds) (Floresco et al, 2003). Phasic DA release has been linked specifically to the 'updating', 'resetting', or 'gating' of relevant novel information into neural network activation states, which are dynamically altered by these inputs (Barch et al, 2000, 1999; Cohen et al, 2002). At least one plausible mechanism by which this resetting process may be mediated is via phasic D2 receptor activation on GABAergic transmission; it has been specifically demonstrated that D1 and D2 receptor agonists have reciprocal effects on $\mathrm{GABA}_{\mathrm{A}}$ receptors, and that D1 agonists can reverse effects of D2 agonists and vice versa (Seamans et al, 2001).

While neurophysiological and neural network simulations support the idea that the sustained activity of neuronal ensembles is promoted by tonic DA release and D1 transmission, and that changes in these states are promoted by phasic DA release and D2 transmission, it is critical to relate these dynamics of neural network properties and simulations to observable cognitive and behavioral functions. Following extensive background literature, we hypothesize that the stability of neural network activation states in which the PFC neurons are participating is directly related to the capacity to sustain cognitive representations in working memory (ie those periods during tasks when a specific representation must be maintained 'on line' for subsequent processing, for example, during the delay period of a delayed response task), and during periods when there is active maintenance of behavioral response sequences or plans (ie the maintenance of 'on-task' behavior which is a crucial aspect of the 'executive' functions involved in planning and executing sequences of behaviors) (Fuster, 1999; Goldman-Rakic, 1995a, 1995b, 1998). In contrast, we hypothesize that the plasticity of these networks underlies the ability to 'update' or 'reset' the contents of working memory (ie to replace the current cognitive representation with novel task-relevant information), and similarly the ability to introduce novel plans or shifts in current plans into ongoing behavioral programs when there are deviations from expectations or when current responses are recognized as erroneous (ie to switch from one behavioral program to another) (Braver et al, 1999; Braver and Cohen, 1999; Carter et al, 1998; Cohen et al, 2002; Petrides et al, 2002).

It should be noted that the 'updating' functions attributed to phasic DA transmission also have been linked specifically to incentive reward signals and particularly to uncertainty in these signals (Aron et al, 2004b). A parallel role for phasic DA transmission has been suggested for conditioned 
learning, by updating the links between stimulus and response when an expected reward does not occur (Fiorillo et al, 2003; Schultz 2002, 2003).

\section{Stability, Plasticity, and Autoregulation via Mismatch Detection}

While generally, cognitive 'stability' connotes a necessary and beneficial state, excessive stability jeopardizes appropriate flexibility. Increased cognitive stability benefits certain functions, such as working memory maintenance tasks (ie keeping representations 'on line'), sustained attention tasks, and tasks demanding freedom from distraction. On the other hand, excessive stability yields inflexibility and difficulty in responding appropriately to external change by modifying ongoing behavioral programs or shifting attention to new foci. This may result in excessive repetition of maladaptive behaviors, perseveration, stereotypy, and a failure to detect novelty. It may also yield difficulty updating the contents of working memory representations.

In neural network models, a key feature of their autoregulatory capacity is the capacity to switch smoothly from one activation state to another. If a specific activation state is overly stable, then it is particularly difficult and requires substantial additional inputs to change to a new state. These models sometimes use an energy argument to help visualize these processes, whereby a 'hyperstable' state may be seen as a particularly deep trough, which requires high-energy input to exceed the threshold for change in state. In these circumstances, when only a high-energy input can lead to a change in state, there is an increased likelihood that the new state will differ more from the original one compared to the situation when low-energy inputs can generate more subtle state changes. In cognitive terms, this means that excess stability would be associated with difficulty making smooth transitions from one state to another, so transitions between cognitive states may be abrupt and appear more disjointed. This may be manifest as unpredictable behavior emerging in the context of more predictable behavior (Paulus et al, 1999) or in marked departures from one train of thought to another (Hoffman, 1992), both of which are observed in schizophrenia.

It should be noted that many elements of this hypothesis converge with others that have been proposed to help understand the autoregulatory controls governing the maintenance of working memory and behavioral programs, and how these cognitive states may be interrupted, updated, and modified smoothly and efficiently. Pribram and coworkers developed a theory specifying 'stabile' and 'labile' dimensions of attentional control under the influence of tonic and phasic arousal processes, respectively (Douglas and Pribram, 1969; McGuinness and Pribram, 1980; Pribram and McGuinness, 1975). Similarly, Jeffrey Gray and co-workers developed a neuropsychological theory of anxiety that emphasized the importance of the septohippocampal 'stop' system, which putatively interrupts ongoing behavioral programs so that new more adaptive behaviors can be substituted (Gray, 1978; Gray and McNaughton, 1996). This theory and others have stressed the centrality of systems underlying behavioral maintenance and inhibition systems, documented the association of these constructs with enduring personality characteristics, shown that these traits are highly heritable, and related deviations in these traits to anxiety, alcoholism, and schizophrenia (Cloninger, 1986).

The neurochemical distinction between tonic and phasic DA, and the functional distinctions between stabilityenhancing and plasticity-enhancing systems outlined above, are paralleled by a functional-anatomic distinction between archicortical and paleocortical systems (Bilder, 1997; Christensen and Bilder, 2000; Cornblatt et al, 2001; Gunduz et al, 1999). It has been suggested that cognitive stability is mediated by tonic activation within the dorsal and medial (archicortical) system, centering on the frontal cortex and dorsal striatum, while cognitive flexibility is mediated via phasic arousal within the ventrolateral (paleocortical) system centering on amygdala and orbitofrontal cortex (Bilder, 1997; Christensen and Bilder, 2000). This hypothesis may help understand studies showing distinctive regional patterns of activation during specific behavioral tasks or impairments following localized lesions. For example, multiple studies converge in the identification of dorsomedial and dorsolateral prefrontal activations during the maintenance phases of working memory tasks, while the orbitofrontal and ventrolateral frontal divisions are selectively activated by tasks that demand switching, reversal, or inhibition of previously rewarded responses, and lesions to these regions result in impairments of these functions (Aron et al, 2004a; Fletcher and Henson, 2001; Menon et al, 2002; Monchi et al, 2001; Petrides et al, 2002).

Each of these models has relied, in part, on the idea that specific systems must underlie the capacity to sustain selected brain activation states when these are adaptive, and interrupt these states and foster substitution of novel more adaptive states when called for by the exigencies of the environment. These models and others propose that a 'comparator' function enables detection of 'mismatch' between expectations and current environmental inputs. The operation of both cellular architectures that support selective maintenance of adaptively advantageous activation states, and the resetting of these states under mismatch conditions, have been formalized in neural network models to help understand a broad range of disorders including schizophrenia, attention deficit disorder, parkinsonism, and depression (Grossberg, 1999). While there are multiple systems (including cortical-cortical, -limbic, and -striatal) that work together to support these complex functions, we propose that tonic and phasic DA transmission play critical roles (respectively) in the stability and plasticity of cognitive control.

In summary, we hypothesize that Met and Val alleles of the COMT Val ${ }^{158} \mathrm{Met}$ polymorphism operate, respectively, to enhance the stability and plasticity of the neural network activation states that mediate the maintenance and updating of working memory/executive functions. More specifically, we suggest that the overall effect of the COMT Val ${ }^{158} \mathrm{Met}$ polymorphism is as follows:

1. The Val allele, associated with high-activity COMT, increases phasic and reduces tonic DA transmission 
subcortically and decreases DA concentrations cortically. This leads to an increase in D2 and a decrease in D1 transmission; as a result, there is decreased stability of neural networks underlying working memory representations, including those that are responsible for the maintenance of behavioral programming (executive) functions, but there is also facilitation of the switching or transition to alternate network states mediating the resetting of working memory traces and flexibility in behavioral programs.

2. The Met allele, associated with low-activity COMT, decreases phasic and increases tonic DA transmission subcortically, and increases DA concentrations cortically; this is associated with increased D1 and decreased D2 transmission in the PFC. This increases the stability of networks mediating sustained working memory representations, but makes it more difficult to switch or update the currently active networks that represent sustained working memory representations or ongoing behavioral programs.

The hypothesized role of the COMT $\mathrm{Val}^{158}$ Met polymorphism in relation to tonic-phasic DA, network stability, and related functional-anatomic systems is summarized in Table 1.

From this perspective, it is possible to consider the varied phenotypic associations already reported for the COMT $\mathrm{Va}^{158}$ Met polymorphism, and to assess the explanatory value of this hypothesis.

\section{REVIEW OF PHENOTYPIC ASSOCIATIONS WITH THE COMT VAL ${ }^{158}$ MET POLYMORPHISM}

\section{Neurocognitive Functions}

Given the critical roles played by catecholamines in a broad range of cognitive functions, significant manipulation of COMT activity would be expected to have cognitive consequences. The COMT inhibitor tolcapone has been found to yield improvements in lesion- or drug-induced deficits of memory and working memory in rats (Khromova et al, 1995, 1997; Liljequist et al, 1997) and to yield wideranging cognitive improvements in patients with Parkinson's disease (Gasparini et al, 1997). These findings can be seen as a product of enhancing tonic DA in cases where its availability was limited by experiment or disease.

At least eight studies so far have examined associations of COMT genotype with various cognitive abilities in healthy individuals and/or people with schizophrenia (Bilder et al, 2002; Diamond et al, 2004; Egan et al, 2001; Goldberg et al, 2003; Joober et al, 2002; Malhotra et al, 2002; Nolan et al, 2004; Tsai et al, 2003). None of these was designed to test the hypothesis of association with cognitive stability or plasticity, but all studies had some focus on assessing the integrity of functions often associated with the PFC. These studies show a broad range of effect sizes relating cognitive phenotype with genotype, ranging from 0 to $42 \%$ shared variance, and thus comparing the results from different tasks across studies may be informative.

Five studies included results from the Wisconsin Card Sorting Test (WCST). During the WCST, subjects are shown

Table I Hypothesized Effects of COMT Polymorphism on Neural Dynamics and Selected Phenotypes

COMT Val ${ }^{158}$ Met polymorphism: allele $=$

\begin{tabular}{|c|c|c|}
\hline \multirow[b]{2}{*}{ Effect on } & \\
\hline & Met & Val \\
\hline COMT (enzyme activity) & Low activity & High activity \\
\hline $\begin{array}{l}\text { Synaptic DA transmission; } \\
\text { tonic-phasic DA model }\end{array}$ & $\begin{array}{l}\uparrow \text { Tonic DA (extraneuronal) and } \downarrow \text { phasic DA (synaptic) } \\
\text { subcortically, increased DA in cortex }\end{array}$ & $\begin{array}{l}\downarrow \text { Tonic DA (extraneuronal) and } \uparrow \text { phasic DA (synaptic) } \\
\text { subcortically, decreased DA in cortex }\end{array}$ \\
\hline $\begin{array}{l}\text { Computational models of PFC and } \\
\text { working memory function }\end{array}$ & $\begin{array}{l}\uparrow \mathrm{DI} \text { transmission; persistent } \mathrm{Na}(+) \text { and } \mathrm{NMDA} \\
\uparrow \text { working memory maintenance functions }\end{array}$ & $\begin{array}{l}\uparrow D 2 \text { transmission; AMPA; } \uparrow \text { working memory 'resetting' } \\
\text { and 'updating' }\end{array}$ \\
\hline Dual cytoarchitectonic trends theory & $\begin{array}{l}\uparrow \text { Archicortical (activation), redundancy bias; mediated by } \\
\text { medial and dorsal frontal cortex/dorsal striatum }\end{array}$ & $\begin{array}{l}\uparrow \text { Paleocortical (arousal), novelty bias; mediated by orbital } \\
\text { and ventrolateral frontal cortex/amygdala-ventral striatum }\end{array}$ \\
\hline Primary cognitive effect & $\begin{array}{l}\text { Benefits on tasks demanding stability (maintenance phases } \\
\text { of working memory, sustained execution of prepotent } \\
\text { response sets), but may show excessive cognitive rigidity } \\
\text { (difficulty updating or switching) }\end{array}$ & $\begin{array}{l}\text { Benefits on tasks demanding flexibility (updating contents } \\
\text { of working memory, switching to novel task), but may lack } \\
\text { cognitive stability (increased distractibility, loss of cognitive } \\
\text { sets) }\end{array}$ \\
\hline $\begin{array}{l}\text { Schizophrenia: symptoms and } \\
\text { sampling issues }\end{array}$ & $\begin{array}{l}\text { More severe negative symptoms; more common in } \\
\text { chronic inpatient samples }\end{array}$ & $\begin{array}{l}\text { More likely to show positive and reactive symptoms; } \\
\text { more common in community samples }\end{array}$ \\
\hline Role in alcoholism and alcohol abuse & $\begin{array}{l}\text { Associated with increased Type I alcoholism and greater } \\
\text { alcohol use }\end{array}$ & $\begin{array}{l}\text { Associated with decreased risk for Type alcoholism and } \\
\text { less alcohol use }\end{array}$ \\
\hline Role in violent/aggressive behavior & $\begin{array}{l}\text { Associated with higher propensity for impulsive-- } \\
\text { aggressive behavior, especially in males }\end{array}$ & $\begin{array}{l}\text { Associated with lower propensity for impulsive- } \\
\text { aggressive behavior, especially in males }\end{array}$ \\
\hline Role in obsessive-compulsive disorder & $\begin{array}{l}\text { Increased risk, particularly for comorbid OCD-tic } \\
\text { disorders }\end{array}$ & $\begin{array}{l}\text { Decreased risk, particularly for comorbid OCD-tic } \\
\text { disorders }\end{array}$ \\
\hline
\end{tabular}


stimulus cards that differ in the color, form, and number of stimuli, and they must discern which characteristic is 'correct' to match the cards with samples, based on feedback from the examiner. After subjects reach a criterion number of correct sorts, and without warning, the examiner changes the correct sorting principle. In two studies, better WCST performance was associated with the Met allele (Egan et al, 2001; Malhotra et al, 2002), two others showed nonsignificant trends in the same direction (Bilder et al, 2002; Joober et al, 2002), and a fifth found no relationship (Tsai et al, 2003). Several of these studies also showed some cognitive specificity, insofar as COMT genotype was not associated with measures of general IQ or reading skill (Bilder et al, 2002; Egan et al, 2001; Joober et al, 2002). The strength of association was modest, however, with no study revealing more than $5 \%$ shared variance between the WCST scores and genotype.

Unfortunately, while the WCST is widely cited as a measure of 'cognitive flexibility' and the most widely used measure of 'perseverative errors' would intuitively appear to offer a direct index of excess rigidity in behavioral programming, the WCST is actually very complex, involves multiple additional functions (including hypothesis generation and conceptualization, self-monitoring, and error correction), and ultimately does a very poor job at differentiating deficits in cognitive stability from those in cognitive flexibility. Among the 11 widely calculated indices of the WCST performance, some (eg 'failure to maintain set') may be particularly valid measures of deficits in cognitive stability, but these error types are so infrequent that they are too insensitive for most research applications.

Another widely used test of PFC function is the ' $n$-back' test, in which subjects must determine in a given trial whether the stimulus is the same as or different from another stimulus presented ' $n$ ' trials ago (eg in the ' 1 -back', subjects respond positively if the stimulus is the same as that shown on the prior trial; while in the '2-back', subjects should only respond positively if the stimulus is the same as that shown in the previous two trials). The Met allele was associated with ' $n$-back' working memory performance in one study (Goldberg et al, 2003), albeit the strength of this association was similar to that observed for the WCST measures (ie shared variance with COMT genotype was less than $3 \%)$. Like the WCST, $n$-back task performance is influenced by both stability and plasticity functions, because success requires both the maintenance of prior stimulus traces over time (stability) and updating of the currently relevant stimulus trace with novel information (plasticity). Goldberg et al (2003) noted that there was no interaction of genotype with ' $n$ ' across the 1-back and 2back conditions, but this does not help disentangle maintenance from updating demands since these are confounded in the $n$-back task (ie as ' $n$ ' increases, so do demands for both maintenance of the 'old' and updating with the 'new' stimuli).

Other measures may show more robust relations with COMT genotype. For example, a composite index of processing speed and attention shared approximately $11 \%$ variance with the COMT $\mathrm{Val}^{158} \mathrm{Met}$ polymorphism in one study (Bilder et al, 2002). The specific individual tasks comprising this index on which better scores were associated with the Met allele (Digit Symbol, Trails A, and
Trails B; all these tasks require rapid visual scanning and writing or drawing of responses) can be seen as benefiting from increased stability and maintenance of sustained attention, but each of these tasks also benefits from plasticity/flexibility in scanning the stimuli and organizing responses. It is interesting that other individual test variables showing the strongest individual associations with the Met allele (greater than $10 \%$ shared variance with genotype) included the Visual Reproductions subtest of the Wechsler Memory Scale - Revised (which demands recall of briefly presented visual figures) and the Hopkins Verbal Learning Test (which demands recall of word lists read to the subjects) (Bilder et al, 2002). These findings are equivocal but more consistent with the role of the Met allele in enhancing stability and maintenance, rather than flexibility of cognitive function.

A recent study of healthy children reported a cognitive phenotype sharing $\sim 26 \%$ variance with COMT genotype (Diamond et al, 2004). The authors examined two tests known to be sensitive to prefrontal lesions. One of these was validated as sensitive to DA manipulations (the 'DotsMixed' task, which is performed poorly both by non-human primates, who have had experimental depletion of prefrontal DA, and by children with phenylketonuria, who are hypothesized to have low prefrontal DA concentrations), while the other ('self-ordered pointing' task) is insensitive to putative DA levels assessed in similar models. On the Dots task, subjects see two different kinds of circles ('dots', either shaded or striped) that can appear either on the left or right side of a video display, and learn to respond with a left or right key press; for one kind of dot the correct response is on the same side that the dot appears ('congruent' condition), while for the other kind of dot the correct response is on the opposite side ('incongruent' condition) (the kind of dot, shaded or striped, that is associated with congruent or incongruent responding is counterbalanced across subjects). In the 'mixed dots' condition, there are equal numbers of congruent and incongruent trials. Diamond and co-workers found that the Met allele was associated with better accuracy on the mixed dots condition, while performance on both congruent and incongruent conditions was not associated with genotype. Consistent with their hypothesis, there was no association of genotype with the 'nondopaminergic' selfordered pointing task. These results appear to argue against our hypothesis, insofar as we would expect that the mixed condition, which putatively has greater demands on the switching of cognitive sets, might be more challenging for subjects with the Met allele. As the authors point out, however, the mixed condition requires simultaneous maintenance of the two rules, and does not specifically segregate performance on the 'switching' component relative to the congruent condition.

We examined effects of the COMT polymorphism on cognitive stability and plasticity using the Competing Programs test in a sample of people with schizophrenia (Nolan et al, 2004). Like the Dots-Mixed test, this test involves subjects learning a two-choice response (a simple 'imitation' condition where the subject presses once on a key in response to a single stimulus, or twice in response to two stimuli), and then reversing this rule (in the 'competing' condition subjects press twice in response to a single 
stimulus and once in response to two stimuli). Learning and retention of the 'imitation' response requires both cognitive flexibility and stability, while learning the 'competing' reversal rule requires flexibility to switch the stimulusresponse contingency and inhibition of the previously learned and more intuitive response. In contrast to the Dots-Mixed task, however, the Competing Programs task runs subjects on a series of imitation trials and then without warning changes to a series of reversal trials, and thus explicitly enables assessment of the 'cost' involved in switching to a novel behavioral program. We found that the Met (relative to the Val) allele was associated with better acquisition of the imitation rule, but also with an increased cost when patients had to switch to the reversal condition. The adverse effect of the Met allele on switching was significant for both accuracy and reaction time measures. Moreover, an index of 'switch-cost' (ie the cost of switching, controlling for overall performance) shared $42 \%$ variance with genotype, substantially higher than has been reported for other phenotypes.

One challenge in interpreting results from reversal learning studies centers on the degree to which reversal can be considered to require more flexibility than initial learning. Logically one might assume that initial learning of a conditioned discrimination involves the same kind of 'switching' (ie from whatever the organism was doing prior to learning) that is involved in learning a reversal (ie reversal could be considered just another discrimination). Lesion studies in humans and non-human primates reveal, however, that learning is much easier when stimulus and response are 'congruent' (eg pressing a left button in response to a stimulus on the left) compared to when these are incongruent (eg pressing a button opposite the side of the stimulus); damage to ventral frontal regions may result in pathological inability to switch to an incongruent response; indeed, this tendency has been seen as the foundation of echophraxia (Goldberg and Bilder, 1987; Luria, 1980; Pribram, 1987). In situations where there is no obvious congruent stimulus-response association (eg new learning of conditioned discriminations for rodents), phasic DA is selectively involved when a newly rewarded association is acquired, but once it is learned there is no DA activation unless there is a change in the paradigm (ie if another secondary cue is added to precede the primary cue, then DA is activated until that is learned)(Fiorillo et al, 2003; Schultz, 2002, 2003). Similarly, functional MRI has demonstrated mesencephalic activations (within the ventral tegmental area, origin of the mesocortical and mesolimbic DA projections) selectively when humans are processing uncertainty (Aron et al, 2004b). These findings converge to suggest that phasic DA response may occur selectively under conditions when the organism is required to switch from a prepotent response, whether that prepotency is recently learned or part of a longer term learning history.

While the studies of neurocognitive function reviewed above are not conclusive, and each has flaws that limit interpretation, it is striking that the two studies with the largest effect sizes (Diamond et al, 2004; Nolan et al, 2004) used tasks that involve relatively simple reversal or 'conflict' paradigms that require the maintenance and switching of response sets. These simple procedures, perhaps by limiting the influence of more complex cognitive processes that are likely to depend on a broad range of additional systems, appear to have promise in gaining better understanding of the cognitive phenotype most related to the COMT $\mathrm{Val}^{158}$ Met polymorphism. It seems reasonable to further investigate the relative roles of set maintenance, switching, and response inhibition in future investigations of this polymorphism.

\section{Cognitive Effects of Stimulants}

A large literature describes the behavioral impact of stimulants, and some studies have examined their effects on cognitive stability and plasticity. The neurochemical effects of stimulants are complex, involving both effects on DA reuptake and storage/release, and thus the effects on tonic and phasic DA are also complicated. Early literature led to the hypothesis that stimulants increase the frequency of responding in a reduced number of behavioral categories (Lyon and Robbins, 1975). According to our hypothesis, this restriction of the response repertoire should be associated with increased stability or reduced flexibility, putatively linked to increases in tonic or decreases in phasic DA function.

Interestingly, there appear to be dose-dependent effects of stimulants, supporting the idea that at low doses, they enhance phasic DA transmission primarily by blocking reuptake of released DA, which is supported by the ability of low doses of amphetamine to produce displacement of raclopride from presumed intrasynaptic sites during human imaging studies (Laruelle and Abi-Dargham, 1999). On the other hand, higher doses of amphetamine may preferentially increase tonic transmission via a direct release from terminals. These latter effects may have predominated in the studies conducted and surveyed by Lyon and Robbins. In more recent behavioral studies in animals, low-dose amphetamine was found to increase the variability and unpredictability, while higher doses increased the predictability and redundancy of behavioral sequences (Paulus et al, 1993).

We have also reported reciprocal effects of conventional antipsychotic drugs and methylphenidate $(\mathrm{MPH})$ in people with schizophrenia. Specifically, increasing putative levels of tonic DA were found to increase perseverative and decrease nonperseverative errors in a fluency task (Bilder et al, 1992). In the context of these findings, it is interesting that amphetamine effects on fMRI activations elicited by WCST and $n$-back task performance depended on COMT genotype (Mattay et al, 2003). In this study, individuals with the Met allele suffered adverse consequences of amphetamine (less efficient prefrontal function), while those with the Val allele appeared to benefit. We would interpret these findings as reflecting an excess of tonic DA transmission in individuals with the Met allele under amphetamine (comparable to a high-dose stimulant exposure), while individuals with the $\mathrm{Val}$ allele were actually helped by having tonic DA increased.

\section{Psychotic Disorders}

Several lines of evidence have suggested that the COMT $\mathrm{Val}^{158} \mathrm{Met}$ polymorphism may relate to susceptibility to schizophrenia. The original DA hypothesis of schizophrenia 
that posited a general excess of dopaminergic activity in the brain would suggest that high COMT activity would exert a protective effect by reducing the amount of DA available for neurotransmission. This conceptualization seemed compatible with the presence of schizophreniform symptoms in some patients with microdeletions on chromosome 22q11 that involve the COMT gene, and indeed a recent metaanalysis of genome-wide linkage studies identified chromosome $22 \mathrm{q}$ as one of only three loci that continue to be good candidates for a schizophrenia-relevant gene (Badner and Gershon, 2002). These considerations lead to a prediction that the Met allele would elevate the susceptibility to schizophrenia. Some recent theories of schizophrenia postulate instead a hypodopaminergic state in the PFC (presumably related to negative symptoms and cognitive impairment) and a dysregulated dopaminergic state subcortically (perhaps associated with positive symptoms) (Weinberger et al, 2001). Prefrontal hypodopaminergia could be due, in part, to an increased catabolism of DA by a more active form of the COMT. Thus, as Weinberger et al infer, the Val allele would elevate the susceptibility to schizophrenia.

The evidence linking the COMT Val ${ }^{158}$ Met polymorphism to schizophrenia as a phenotype was regarded as inconclusive in a recent meta-analysis of 14 case-control and five family-based association studies, albeit the authors suggested that the Val allele may confer a modest increase in risk for schizophrenia, particularly in European populations (Glatt et al, 2003). Not included in this meta-analysis was a large case-control study of Ashkenazi Jews who provided strong evidence for an association of the COMT gene with schizophrenia, albeit the association was stronger for two nearby SNPs (rs737865 and rs165599) than for the $\mathrm{Val}^{158}$ Met polymorphism (rs165688) (Shifman et al, 2002).

The authors of the meta-analysis acknowledge that phenotypic heterogeneity may play a role in discrepancies between studies and particularly in the divergent results from family-based and case-control studies; specifically, family-based studies are biased to include participants with higher levels of social support and involvement, or less severe pathology (Glatt et al, 2003). Supporting this interpretation, the studies that found an excess of the Met allele among patients included particularly impaired groups recruited principally from inpatient settings (Ohmori et al, 1998; Strous et al, 1997), while those reporting stronger associations with the Val allele involved patients primarily recruited from the community (for further descriptions see Egan et al, 2000; Li et al, 1996).

The hypothesis that more severe/chronic schizophrenia may be associated with Met and milder forms of schizophrenia with the Val allele is supported by a (post hoc) analysis of 129 unrelated schizophrenia patients (Herken and Erdal, 2001), indicating that the Met allele is associated with higher severity of symptoms (measured by the BPRS; Overall and Gorham, 1962) and with more frequent hospitalization. Another study reported that more severe symptoms of schizophrenia (particularly negative symptoms) were associated with the Met allele, despite the observation in the same study that the Met allele was associated with better performance on neurocognitive tests (Bilder et al, 2002). The hypothesis associating the more severe form of schizophrenia with the Met allele is consistent with the finding that this allele may be associated with treatment resistance (Illi et al, 2003a, b).

According to the hypothesis presented here, the schizophrenia phenotype may be associated with defects in either tonic or phasic DA transmission due to different vulnerabilities.

Excessive tonic DA transmission is suggested to yield excessive stability of neuronal activation states, which in turn are suggested to yield excessive levels of cognitive rigidity, and vulnerability to persistent symptom states that are refractory to treatment with conventional antipsychotic agents (see also below), increased likelihood of negative symptoms, and the deficit syndrome. Excessive phasic DA transmission is suggested to yield instability of neuronal activation states, associated cognitive symptoms reflecting failure to sustain attention, easy distractibility or disruption of plans, more 'positive' symptoms, and a more 'reactive' form of the schizophrenia syndrome.

From this theoretical position, it can be hypothesized that the Met allele, leading to increased tonic and reduced phasic DA, may be associated with a vulnerability to the schizophrenia syndrome that is characterized by negative symptoms and pathologic inflexibility, while the Val allele, leading to decreased tonic DA and increased phasic DA, may be associated with a form of the syndrome prone to show positive symptoms, reactive disorganization and hyperarousal to what are usually innocuous stressors. Similar arguments were previously advanced to describe different vulnerabilities and treatment options associated with archicortical and paleocortical anatomic systems (Bilder, 1997; Christensen and Bilder, 2000; Lencz et al, 2001a,b).

Following the rationale that D1 receptors are more critical for tonic and D2 receptors more critical for phasic DA modulation in subcortical regions, and in the PFC, it could further be hypothesized that the vulnerability posed by the $\mathrm{Val}$ allele might have more favorable treatment response to D2 antagonists, while the vulnerability associated with the Met allele might have less favorable response to D2 antagonists. Data supporting this hypothesis come from reports showing that suboptimal responders to conventional antipsychotic drug treatment were more likely to have the Met allele of the COMT Val ${ }^{158}$ Met polymorphism (Illi et al, 2003a,b), and further that this vulnerability interacts with a functional polymorphism affecting monamine oxidase A (MAOA) activity (Illi et al, 2003b). A parallel finding was reported in a Japanese sample, where patients carrying the Met allele required higher daily neuroleptic drug doses during maintenance treatment (Inada et al, 2003). Similarly, we would predict that COMT inhibitors, such as tolcapone, might be beneficial preferentially in individuals who have highest COMT activity (ie Val homozygotes). Complementarily, we would hypothesize that individuals with the Met allele might be better treated with D1 agonists or DA system stabilizers, a mechanism proposed for the new antipsychotic aripiprazole (Stahl, 2001a,b). It is also possible that individuals with the Met allele might benefit preferentially from treatments that indirectly increase tonic DA transmission, such as the noncompetitive NMDA receptor antagonist memantine (Peeters et al, 2003). Yet, another putative mechanism of 
action for increasing tonic DA transmission may involve serotonergic mechanisms, since 5-HT(2A) antagonism and $5-\mathrm{HT}(1 \mathrm{~A})$ agonism appear to increase medial prefrontal DA release, and these mechanisms have been proposed as possible routes for cognitive enhancing properties of multiple atypical antipsychotic agents including clozapine, risperidone, olanzapine, quetiapine, and ziprasidone (Ichikawa et al, 2001; Meltzer et al, 2003).

It is interesting that among the findings relating COMT genotype to bipolar disorder, Met genotype has been related only to ultra-ultra rapid cycling bipolar disorder. This syndrome is unique in that distinctive shifts in mood and activity may occur within a $24-$ to 48 -h period. The authors interpreted these findings as reflecting a generalized increase in catecholaminergic activity, similar to the mechanisms previously suggested for the induction of rapid cycling by antidepressant treatment (Papolos et al, 1998). We hypothesize that this effect may be more specifically due to increases in tonic DA, leading to activation states that may shift dramatically from one stable configuration to another, and be relatively impervious to environmental exigencies. Similar adverse effects were postulated to result from supranormal DA levels in the PFC, in the context of a detailed biophysical model, resulting in '...uncontrolled network oscillations without any meaningful relation to the stimulus situation' (Durstewitz et al, 1999, p 2817).

\section{Alcoholism}

Genetic factors play a role in the development of alcoholism, but the molecular mechanisms of transmission remain unclear. Two subtypes of alcoholism exist: Type 1, characterized by late onset (after the age of 25 years) and no prominent antisocial behavior, and Type 2, with early onset and impulsive violent behavior (Cloninger, 1987). Type 2 is associated with a polymorphism of the serotonin transporter gene (Hallikainen et al, 1999), but not with COMT polymorphism (Hallikainen et al, 2000). However, the frequency of the COMT Met allele was markedly increased in two independent samples of Type 1 male alcoholics in Finland (Tiihonen et al, 1999). These were convenience samples (total $N=123$ ) compared with general Finnish population (blood donors, $N=3140$ ) and with unrelated matched controls $(N=267)$. Furthermore, an association between the Met-Met genotype and the level of alcohol use was established in an epidemiological sample of middleaged Finnish men $(N=896)$ (Kauhanen et al, 2000). Men with this genotype reported $27 \%$ higher weekly alcohol consumption compared with the Met-Val and Val-Val genotype groups. The authors speculate that the association of the Met allele with drinking alcohol can be understood in the context of dopaminergic mediation of reward processes; ethanol increases phasic dopaminergic activity in the brain, and persons with low COMT enzymatic activity (ie those with the Met-Met genotype) may thus perceive alcohol as more pleasurable than do other people.

However, a family-based study in German subjects did not replicate the results obtained in Finland (Wang et al, 2001). No significant transmission disequilibrium was found in the overall sample of 70 parent/offspring trios, but they did find preferential transmission of the Met allele to patients with an early onset of disease (Type 2). The results of this study are difficult to interpret since the subject set consisted of only 54 males and 16 females; there were 32 Type 1 and 38 Type 2 alcoholic patients. Thus, the sample was small and heterogeneous.

On the other hand, no association between COMT polymorphism and alcoholism was detected in a Japanese case-control study comparing 175 alcoholics with 354 unrelated control subjects (Ishiguro et al, 1999). Most (but not all) of the patients had the late-onset form of alcoholism; $88 \%$ were males. The frequency of the Met-Met genotype among the Japanese patients (and controls) was only $9 \%$; this frequency was much lower than that observed in the Finnish samples (25-30\%). This genotypic difference is consistent with the known population variations in the frequency of the Met allele; Europeans have generally higher frequency of this allele than other populations (Palmatier et al, 1999). The role of the COMT polymorphism in the development of alcoholism thus may not be the same in European and other populations.

While complicated by possible interactions with sex differences and possible population stratification, these findings generally suggest that Type 1 alcoholism and increased alcohol use following the onset of regular drinking may be associated with the Met allele. We believe that understanding this link may depend on understanding the neurobiology of anxiety and how this is impacted by the use of alcohol. Specifically, Jeffrey Gray and co-workers have developed a theory in which alcohol use is seen as moderating septohippocampal activity (ie the behavioral inhibition system or BIS) that is engaged preferentially in circumstances where there is a 'mismatch' between an organism's expectations and the actual circumstances perceived in the environment (Gray, 1978, 1982, 1983, 1985, 1988; Gray and McNaughton, 1996; McNaughton and Gray, 2000). CR Cloninger and co-workers invoked a virtually identical mechanism to explain the harm avoidance' personality trait, which interestingly is found to be elevated preferentially in Type 1 but not Type 2 alcoholism (the latter tend to be higher in novelty seeking) (Braver et al, 1999). According to both of these theories, there are several ways that excessive activity of the BIS (reflecting excessive anxiety) can be stimulated. One way is to present the organism with highly novel stimulation, triggering mismatch with current expectations. Another way is to have an exceptionally sensitive mismatch detection system so that even minor differences between expectations and reality result in BIS activity (which according to these models would usually involve a hippocampal abnormality). A third way to trigger mismatch is by having an overly rigid system for generating expectations, such that the typically changing stimulus world will fail to match expectations because these are not being updated adequately to reflect current environmental inputs. It is this third possibility that would be most compatible with our hypothesis, that the Met allele is associated with excessive rigidity in the frontally mediated neural activation states that represent expectations. Supporting this idea, the Met allele was associated with increased anxiety in two populations of women (Enoch et al, 2003). We suggest that individuals with the Met allele may learn to use alcohol, or use alcohol in higher doses, as a form of self-medication, to attenuate these anxious 'mismatch detection' states. 
Grace offered a compatible explanation that focuses more on the relations of tonic and phasic DA to reward mechanisms (Grace, 2000), and this is consistent with the hypothesis advanced by Kauhanen and co-workers as noted above (Kauhanen et al, 2000). Grace hypothesized that alcohol acts principally by increasing phasic DA activity (resulting in its rewarding properties). According to the hypothesis presented here, if the Met allele produced increased tonic and decreased phasic DA activity, alcohol use would be seen as a form of self-medication to alleviate unrewarding aspects of high tonic DA activity. Grace further hypothesized that with chronic use, tonic DA is increased, causing individuals to require more alcohol to restore the phasic DA response. If the Met allele is associated with increased tonic DA, vulnerable individuals would thus be hypothesized to require higher doses to achieve the same rewarding effect, and to develop chronic abuse/dependence patterns more readily.

\section{Aggression}

Twin and adoption studies provide evidence for genetic influences on criminal and antisocial behavior (Volavka, 2002). Considerable literature indicates that the serotonin system has a potent role in the modulation of aggressive behavior in many species, including humans, but there is also evidence for catecholaminergic contributions. Aggression in rodents is enhanced by L-DOPA (Lammers and Van Rossum, 1968) and by the DA agonist apomorphine (Senault, 1970). Cocaine and amphetamine may induce aggression in humans. These data on DA (and additional data on norepinephrine summarized elsewhere; Volavka, 2002) suggest that COMT can be considered as one of the candidate genes for the regulation of aggressive behavior. Since catecholamine agonists tend to increase aggressive behavior, low enzymatic activity of COMT would be expected to increase the likelihood of aggression. This expectation is supported by the observation that COMT knockout mice exhibited elevated aggressive behavior, albeit this effect was limited to males (Gogos et al, 1998). Furthermore, in male mice, the more aggressive inbred strains had lower COMT expression levels in the hippocampus than the less aggressive strains (Fernandes et al, 2004).

On the basis of the data discussed so far, the Met allele, coding for the lower COMT enzymatic activity, would be considered most likely to be associated with persistent aggressive behavior in humans. A small study of dangerous behavior in schizophrenia patients yielded results consistent with this expectation (Strous et al, 1997). The association of the Met allele with aggression was replicated in another sample of patients diagnosed with schizophrenia or schizoaffective disorder comparing patients with a history of multiple assaults with those who had no history of assault (Lachman et al, 1998). The association also appeared to be more clearly expressed among males in this sample. The patient samples in these two studies (Lachman et al, 1998; Strous et al, 1997) were collected in the New York Metropolitan area; they were ethnically heterogeneous and the possibility of population stratification confounding the results of these two small association studies has been acknowledged. More recently, however, the Met allele was associated with homicidal behavior in schizophrenic (mostly male) patients in Israel (Kotler et al, 1999) and with aggression in Italian patients with bipolar disorder (Rotondo et al, 2002). A recent replication of this association in 122 schizophrenia patients (98 men), in Israel, further supports the association of the Met allele with aggression and violence towards oneself and others (Strous et al, 2003). Furthermore, in a study of treatment-resistant schizophrenia and schizoaffective disorder, the Met-Met homozygotes showed higher levels of hostility than the patients with the Val-Val or the Val-Met genotypes (Volavka et al, 2004). A recent study in Germany of 149 suicide attempters and 328 control subjects found that the Met allele was associated with violent suicide attempts and a greater tendency towards external expression of anger across all subjects (Rujescu et al, 2003). Thus, the association between COMT polymorphism and aggression was observed in six association studies using five different human populations. The results of these human studies are consistent with the observations in COMT knockout mice mentioned above. Rodents and humans even showed the same sexual dimorphism - the effect on aggression was more expressed in males. However, the association between the Met allele and aggression was not replicated in a large sample of schizophrenia patients in Wales (Jones et al, 2001). Unlike some of the positive studies discussed above (Kotler et al, 1999; Lachman et al, 1998), however, the Welsh patients were not selected for violence.

It is clear that any COMT-mediated vulnerability interacts with generalized neurological impairment and other neuromodulators (Volavka, 2002), but the findings of multiple studies converge to suggest that lower COMT enzyme activity (Met allele in humans and the COMT 'knockout' genotype in rodents) is associated with aggression. Our hypothesis suggests that low-activity COMT is linked to increased tonic DA activation, decreased flexibility in responding, and difficulty in the smooth and effective modulation of response selection in response to novel or changing environmental exigencies. While future research should more clearly target the distinction between 'impulsive' and 'planned' aggression in their associations with COMT genotype, it is most likely that the evidence accumulated so far pertains largely to unplanned or impulsive aggressive episodes (Nolan et al, 2003). Individuals with limited cognitive flexibility may have difficulty responding adaptively to perceived challenges to their current plans. Cohen et al (2002, p 223) suggested that excesses of tonic DA activity might lead to a condition in which 'performance may degrade as PFC representations become overly fixed and brittle' . By 'brittleness' Cohen and co-workers are invoking a concept derived from neural network simulations, in which high-energy input may be required to overcome and change a particular activation state, and in these circumstances the resulting new activation state may diverge markedly from the original state. Thus, a disadvantage of excessively stable activation states is that these make smooth transitions to similar states more difficult and, instead, the 'jump' to a new activation state (and new behavior) will be more dramatic.

We suggest that this excessive rigidity is a key feature of certain patients' responses to external challenges, particularly for patients who show impulsive aggression. These 
patients may 'skip' the gradual buildup of hostility that usually precedes the onset of physical aggression and is manifested by changes in facial expression demonstrating anger, body language such as pacing with clenched fists, and verbal aggression. We hypothesize that these transitional processes are associated with the Val allele, which permits more phasic changes in underlying neural activation states. If this is true, then state changes occurring in response to external stressors may reduce the sense of conflict that is experienced, thus decreasing the urge to physical aggression. Instead, the more graded expression of these state changes may even warn potential victims so that they can take evasive action or provide sufficient time for personnel to intervene and prevent physical aggression. These mechanisms may thus be involved in an adaptive antiaggressive effect of the Val allele.

In contrast, among impulsive aggressive patients, physical aggression may develop suddenly without any recognizable buildup or observable state change. From extensive interviews with assailants and their victims, we have found that patients who suddenly assault others without any immediate provocation may actually be responding to perceived threats, insults, or fights that occurred several days earlier. It appears that these patients had been thinking about these previous events for days, unable to switch their attention to other topics. If our hypothesis has merit, this kind of fixed ideation may also be an expression of excessive tonic DA transmission associated with the Met allele.

\section{Attention Deficit Hyperactivity Disorder (ADHD) and Tourette's Syndrome (TS)}

Research on ADHD has made substantial progress in identifying risk genes for the clinical phenotype, and understanding the genetics of this syndrome is of high relevance to the current hypothesis, given that theories of the syndrome center on the role of DA neurotransmission, supported principally by the established efficacy of stimulant drugs in its treatment. At least four polymorphisms that impact DA neurotransmission have been implicated (DAT 1, DRD 4, DBH, and DRD 5) and arguments support the likelihood that the ADHD phenotype shows a multifactorial and polygenic inheritance (for a review see Comings, 2001).

Most investigations of the COMT $\mathrm{Val}^{158}$ Met polymorphism have been negative (Barr et al, 1999a; Hawi et al, 2000; Kirley et al, 2002a, b; Payton et al, 2001; Tahir et al, 2000), but there are a few (unreplicated) positive reports. Eisenberg et al (1999), using a haplotype relative risk design and a parent-to-proband allele transmission test with 48 ADHD triads in Israel, found an association of the $\mathrm{Val}$ allele with the DSM-IV ADHD diagnosis, and slightly stronger effects when diagnosis was restricted to the impulsive-hyperactive type. The same group of investigators, however, failed to replicate this finding both in a separate group of 70 nuclear families, and in the overall expanded cohort of 118 triads (Manor et al, 2000). Possibly contrasting findings were reported in a larger study of Han Chinese individuals, employing transmission disequilibrium test, haplotype-based haplotype relative risk (HHRR), and case-control analyses (Qian et al, 2003). The HHRR analysis suggested that the low enzyme-activity
COMT Met allele was preferentially transmitted to ADHD boys but not girls, while the case-control study revealed that the Val allele was more frequent in female cases compared to controls. A separate case-control study in the Han Chinese population found no relationship between ADHD diagnosis and the COMT Val ${ }^{158}$ Met polymorphism (Zhang et al, 2003). These results provide no clear support for a role of the COMT $\mathrm{Val}^{158} \mathrm{Met}$ polymorphism in association with the ADHD phenotype.

Despite the lack of association of the ADHD phenotype with the COMT $\mathrm{Val}^{158}$ Met polymorphism, it may nevertheless be important that some consistent evidence supports an association of ADHD with the DAT 1 polymorphism, particularly given that the putative mechanism of action of stimulant drugs effective in ADHD is their tendency to block the DAT. These findings, together with additional evidence from neuropharmacological studies in non-human species and brain imaging studies in humans, support a 'hypodopaminergic' hypothesis of ADHD, which suggests that there is decreased DA neurotransmission in the striatum (for a review see Kirley et al, 2002b). Volkow and Swanson (2003) recently summarized evidence supporting the idea that the therapeutic effects of MPH are mediated by enhancement of tonic rather than phasic DA release. If this is true, we would predict that individuals with the Met allele are more likely to benefit from lower doses of $\mathrm{MPH}$. It is interesting in this respect that Sonuga-Bark distinguished two types of deficit in ADHD that are independent: one a 'cognitive' inhibition deficit putatively related to mesocortical DA and the other a 'reward' sensitivity deficit putatively linked to mesolimbic DA (Sonuga-Barke, 2003). Volkow and Swanson (2003) also found that $\mathrm{MPH}$ effects on DAT blockade and DA release are independent, and suggested that these individual differences may help explain the marked differences in treatment response and dosing needed for clinical benefits. It may therefore be most logical to assume, for this complex syndrome, that studies of the COMT Val ${ }^{158}$ Met polymorphism would focus better on its possible role as a modulator of treatment response, or its relations to more specific cognitive or motivational subsyndromes, or its interactions with other genes, rather than focus on studying associations of a single gene with the diagnosis of ADHD. One potentially fruitful conceptual approach may be that proposed by Comings et al (2000), who used multivariate analysis of association in a study of 42 genes to suggest that ADHD loads most heavily on genes regulating norepinephrine, but that the COMT $\mathrm{Val}^{158} \mathrm{Met}$ polymorphism may explain $\sim 2.5 \%$ of the variance in ADHD score.

TS is a rare syndrome $(\sim 1 / 10000)$ involving motor and vocal tics, which is frequently complicated by comorbid OCD or ADHD. Given the heritability of TS, the fact that DA dysfunction in the basal ganglia has been seen as central to its pathophysiology, and the fact that the primary treatment for TS has involved DA(D2) blockade, a relationship with the COMT $\mathrm{Val}^{158}$ Met polymorphism might be suspected. There is a long history of research investigating links of TS to possible abnormalities in peripheral catecholamine metabolites with negative results (Giller et al, 1980; Lake et al, 1977; Shapiro et al, 1984). Investigations of possible association of TS with the COMT Val ${ }^{158}$ Met polymorphism to date have also been negative (Barr et al, 1999b; Cavallini 
et al, 2000). In light of some hypotheses linking TS directly with ADHD as a closely related polygenic disorder, and the at best modest association of ADHD with the COMT $\mathrm{Val}^{158} \mathrm{Met}$ polymorphism, this lack of positive evidence might be expected (Comings, 2001).

\section{Obsessive-Compulsive Disorder (OCD)}

OCD has a genetic component (Pauls and Alsobrook, 1999), but the mode of inheritance has not been clarified. Dysfunctions of the serotonin system have been suggested as the primary neurochemical mechanisms underlying this illness in most patients, but dopaminergic mechanisms may also be involved. This involvement is suggested by the fact that the addition of DA antagonist agents to fluvoxamine significantly improved OCD symptoms in patients whose response to fluvoxamine alone was suboptimal (McDougle et al, 1990, 1994a, b). This response was particularly pronounced in patients who have comorbid tics or who have a family history of tics. An involvement of DA in the pathogenesis of OCD would suggest that COMT is a candidate gene in the modulation of OCD expression.

An association study comparing 78 OCD patients with 148 unrelated control subjects indicated that the Met allele was associated with OCD in the male but not female patients (Karayiorgou et al, 1997). These results were supported by a family-based study implemented by the same research group (Karayiorgou et al, 1999). A total of 110 nuclear OCD families were studied; it is not clear whether the patient sample overlapped with the set reported previously (Karayiorgou et al, 1997). However, these results could not be replicated by other authors in case-control studies (Ohara et al, 1998; Niehaus et al, 2001) or in family-based studies (Schindler et al, 2000). One family-based study indicated a weak association between the Met allele and OCD in females, but not in males (Alsobrook et al, 2002). Moreover, a recent meta-analysis found little support for the association of the COMT Val ${ }^{158}$ Met polymorphism and OCD, even after considering a possible modulating effect of gender.

It is likely that OCD has phenotypic subtypes that are represented in variable proportions across different patient samples. The subtypes may have different underlying neurochemical and genetic bases. For example, the fact that DA blockers are particularly helpful to OCD patients who have tics would suggest that the Met allele would be more plentiful among this subpopulation. This was suggested by data in one study (Karayiorgou et al, 1997), but comorbid tics were apparently not ascertained in subsequent studies.

Findings suggesting that certain variants of OCD are associated with the Met allele would fit well with the tonicphasic DA hypothesis. Increased levels of tonic DA associated with the Met genotype would be predicted to yield greater vulnerability to maintain maladaptive behaviors and excessive fixedness of behavioral programs, regardless of external inputs. This agrees well with DSMIV definitions of obsessions (persistent ideas, thoughts, impulses, or images, etc) and compulsions (repetitive behaviors, etc) (American Psychiatric Association, 1994, $\mathrm{p}$ 418). Other evidence reveals parallels between cognitive findings in OCD patients and patients with orbital frontal damage. Studies show that OCD patients have both structural and functional neuroimaging findings compatible with orbital frontal cortex and amygdala dysfunction, along with relative sparing of superior frontal, anterior cingulate, and hippocampal structure; these findings were interpreted as reflecting excessive tonic activation operating without appropriate modulation by phasic arousal (Christensen and Bilder, 2000; Szeszko et al, 1999). These observations would agree well with the current hypothesis associating the Met allele with increased tonic and decreased phasic DA transmission.

\section{DIRECTIONS FOR FUTURE RESEARCH}

This review offers speculative theoretical explanations about how the COMT polymorphism may account for a diversity of findings. We believe the tonic-phasic DA model may offer greater explanatory power and comprise an initial framework for the next generation of neurochemical, cognitive, and functional neuroimaging experiments that can help refine the phenotype most closely associated with the COMT genotype. Several experimental approaches could determine if there is merit in this hypothetical explanation of COMT effects on behavior and human illness.

\section{Direct Neurochemical and Physiological Studies}

Evidence already exists showing region-specific increases in steady-state prefrontal DA concentrations (presumably tonic DA) in COMT-deficient compared to wild-type mice (Gogos et al, 1998). Experiments on these mutants could be augmented by in vivo microdialysis and single unit recordings to determine more specifically that tonic DA concentrations are increased without major contributions from phasic DA release, in response to specific D1 and D2 receptor agonists/antagonists (Parsons and Justice, 1992; West et al, 2002). If this polymorphism can be identified in non-human species, another direct approach could involve comparing DA levels in PFC relative to subcortical regions, to determine empirically the impact of the different alleles on the cortical:subcortical DA ratio. Thus, diminished PFC DA has been proposed to lead to hyperactivity within subcortical DA systems of schizophrenia patients (Jaskiw et al, 1990; Pycock et al, 1980). Animals that carry the Val allele would be predicted to respond to challenges, such as stress or amphetamine, with an attenuated cortical DA response, but increased phasic DA subcortically (Grace, 1991). If no non-human parallel to the human COMT $\mathrm{Val}^{158}$ Met polymorphism is identified, similar experiments could be conducted using pharmacological manipulation of COMT enzyme activity.

\section{Human Behavioral and Functional Imaging Studies}

Existing studies showing decreased dorsolateral prefrontal activation during the $n$-back test in individuals with the Met allele are suggestive, but additional experiments could specifically tease apart the working memory maintenance from updating functions. One simple manipulation of this task involves modifying the interstimulus interval (ISI). As the ISI increases, demands for maintenance increase while 
demands for updating decrease. We predict a genotype by ISI interaction effect; specifically individuals with the Met allele should show greater behavioral advantages, and more robust differences in brain activation response, as ISI increases. Several other paradigms may be even better suited to differentiate maintenance from updating functions in working memory, and these might offer promising candidates for defining COMT-relevant phenotypes (Halgren et al, 2002; Kusak et al, 2000; Radvansky, 2001). Similarly, tasks examining the ability to maintain a consistent behavioral program in the face of distraction could help dissect the contributions of reciprocal controls over cognitive stability and plasticity (Fan et al, 2002). Most sensitive may be tasks that examine directly the patterning of sequential responses in terms of their redundancy (predictability) and entropy (unpredictability) (Paulus et al, 1999, 1994, 1996). Cognitive experiments of this type can be applied in large sample studies, and the candidate phenotypes most sensitive to COMT allelic variation may be selected for application in smaller sample functional imaging studies to further refine our understanding of the neural systems engaged in these operations.

\section{Clinical Studies}

It is likely that careful subtyping of clinical samples will be necessary to yield meaningful relations to the genotype. If this hypothesis has merit, for example, individuals with persistent negative syndromes of schizophrenia would be considered more likely to have the Met allele, while those with episodic reactive forms of schizophrenia would be more likely to carry the Val allele. While such symptom dimensions may be cruder and less relevant than neurocognitive and neuroimaging phenotypes, data may already exist in some large clinical samples that would enable preliminary assessment of this hypothesis. Pharmacogenomic strategies might also be informative. For example, individuals with the Met allele are hypothesized to be less likely to respond favorably to D2-blocking agents (a suggestion already supported by some studies (Illi et al, 2003a, b; Inada et al, 2003) and perhaps respond better to D1 agonists, DA system 'stabilizers,' or other agents that indirectly increase tonic DA transmission (eg NMDA antagonists, 5-HT(2A) antagonists, or 5-HT(1A) agonists). Existing data from large randomized controlled trials, in which genotyping has already been conducted, might enable tests of these hypotheses. Another possibility could capitalize on the heterogeneity of stimulant effects on behavior in schizophrenia; in some patients stimulants may reduce negative symptoms and enhance cognitive functions (Daniel et al, 1989; Goldberg et al, 1991), but in other studies stimulants exacerbate positive symptoms (Levy et al, 1993; Lieberman et al, 1984). We would predict that patients with the Val allele (and lower tonic DA activity) might be particularly vulnerable to stimulant-associated positive symptom exacerbation due to phasic DA release. Indeed, studies have shown that patients who show amphetamineinduced exacerbation of positive symptoms also exhibit significantly higher amphetamine-induced raclopride displacement (Laruelle and Abi-Dargham, 1999). Patients with the Met allele, who have higher tonic and lower phasic DA activity, are predicted to respond to stimulants with negative symptom reduction and less risk of positive symptom exacerbation. As noted above in the discussion of neurocognitive phenotypes, however, it may also be possible to 'overdose' the tonic DA system, leading to impaired function, and this might be more common among individuals with the Met allele. This suggestion is consistent with the recently reported results showing that the COMT genotype interacts with amphetamine to produce either beneficial or detrimental results on performance and presumably on brain activation state as measured by fMRI (Mattay et al, 2003).

\section{Complexities of COMT Research}

There are multiple complexities and limitations that need to be considered in interpreting the literature on the COMT $\mathrm{Val}^{158}$ Met polymorphism. Sexual dimorphism has been reported in the relationships of the COMT polymorphism with alcohol use, anxiety, aggression, and OCD. Such dimorphism may exist in other phenotypic expressions of the polymorphism, but it has not been systematically studied. Different proportions of males and females in samples studied may explain some of the inconsistency between reported results, but other factors, such as differential expression of other genes that differ between sexes, and hormonal differences that may modulate the COMT effects, require careful consideration and further study. It is also important to recognize that phenotypic subtypes within broad diagnostic groups such as schizophrenia or alcohol use disorders may have a different relation to the COMT polymorphism. It should also be recognized that COMT is not only involved in the catabolism of DA, but also other catecholamines and catechol estrogens that may play important roles in cognitive and other functions. Finally, differences in complex brain functions are certainly not going to be explained by single genes. For example, preliminary evidence indicates that the relation between the COMT polymorphism and personality is modulated by at least two other genes (DRD4 and 5-HTTLPR) (Benjamin et al, 2000), and the effects of the COMT polymorphism may interact with the MAOA polymorphism to predict a conventional antipsychotic drug response (Illi et al, 2003b). There are also complex interactions of gene effects with environmental circumstances that potently mediate outcomes (Caspi et al, 2002). The aim of this perspective is simply to highlight the possible effects of a single, common, functional polymorphism that may have substantial effects on a range of cognitive and neuropsychiatric phenotypes, and to offer a hypothesis that may help refine the phenotype most closely related to this polymorphism. It is hoped that the outcome of this research may be a fuller explanation of not only COMT polymorphism effects but also the overall regulatory roles served by distinctive systems within the PFC, leading to improved understanding of multiple mental disorders and their treatments.

\section{ACKNOWLEDGEMENTS}

This work was supported by grants from the National Alliance for Research on Schizophrenia and Depression, 
and from the NIMH. The authors thank Daniel Durstewitz for his valuable comments.

\section{REFERENCES}

Alsobrook JP, Zohar AH, Leboyer M, Chabane N, Ebstein RP, Pauls DL (2002). Association between the COMT locus and obsessive-compulsive disorder in females but not males. Am J Med Genet 114: 116-120.

American Psychiatric Association (1994). Diagnostic and Statistical Manual of Mental Disorders (DSM-IV), 4th edn. American Psychiatric Association: Washington, DC.

Aron AR, Robbins TW, Poldrack RA (2004a). Inhibition and the right inferior frontal cortex. Trends Cogn Sci 8: 170-177.

Aron AR, Shohamy D, Clark J, Myers C, Gluck MA, Poldrack RA (2004b). Human midbrain sensitivity to cognitive feedback and uncertainty during classification learning. J Neurophysiol 92: 1144-1152.

Badner JA, Gershon ES (2002). Meta-analysis of whole-genome linkage scans of bipolar disorder and schizophrenia. Mol Psychiatry 7: 405-411.

Barch DM, Braver TS, Sabb FW, Noll DC (2000). Anterior cingulate and the monitoring of response conflict: evidence from an fMRI study of overt verb generation. J Cogn Neurosci 12: 298-309.

Barch DM, Sabb FW, Carter CS, Braver TS, Noll DC, Cohen JD (1999). Overt verbal responding during fMRI scanning: empirical investigations of problems and potential solutions. Neuroimage 10: 642-657.

Barr CL, Wigg K, Malone M, Schachar R, Tannock R, Roberts W et al (1999a). Linkage study of catechol-O-methyltransferase and attention-deficit hyperactivity disorder. Am J Med Genet 88: 710-713.

Barr CL, Wigg KG, Sandor P (1999b). Catechol-O-methyltransferase and Gilles de la Tourette syndrome. Mol Psychiatry 4: 492-495.

Benjamin J, Osher Y, Lichtenberg P, Bachner-Melman R, Gritsenko $\mathrm{I}$, Kotler $\mathrm{M}$ et al (2000). An interaction between the catechol $\mathrm{O}$ methyltransferase and serotonin transporter promoter region polymorphisms contributes to tridimensional personality questionnaire persistence scores in normal subjects. Neuropsychobiology 41: 48-53.

Bilder RM (1997). Neurocognitive impairment in schizophrenia and how it affects treatment options. Can J Psychiatry 42: 255-264.

Bilder RM, Lipschutz-Broch L, Reiter G, Mayerhoff DI, Geisler SH, Lieberman JA (1992). A verbal learning deficit in first episode schizophrenia. J Clin Exp Neuropsychol 14: 122-124.

Bilder RM, Volavka J, Czobor P, Malhotra AK, Kennedy JL, Ni X et al (2002). Neurocognitive correlates of the COMT Val(158)Met polymorphism in chronic schizophrenia. Biol Psychiatry 52: 701-707.

Braver TS, Barch DM, Cohen JD (1999). Cognition and control in schizophrenia: a computational model of dopamine and prefrontal function. Biol Psychiatry 46: 312-328.

Braver TS, Cohen JD (1999). Dopamine, cognitive control, and schizophrenia: the gating model. Prog Brain Res 121: 327-349.

Brunel N, Wang XJ (2001). Effects of neuromodulation in a cortical network model of object working memory dominated by recurrent inhibition. J Comput Neurosci 11: 63-85.

Carter CS, Braver TS, Barch DM, Botvinick MM, Noll D, Cohen JD (1998). Anterior cingulate cortex, error detection, and the online monitoring of performance. Science 280: 747-749.

Caspi A, McClay J, Moffitt TE, Mill J, Martin J, Craig IW et al (2002). Role of genotype in the cycle of violence in maltreated children. Science 297: 851-854.

Cavallini MC, Di Bella D, Catalano M, Bellodi L (2000). An association study between 5-HTTLPR polymorphism, COMT polymorphism, and Tourette's syndrome. Psychiatry Res 97: 93-100.

Christensen BK, Bilder RM (2000). Dual cytoarchitectonic trends: an evolutionary model of frontal lobe functioning and its application to psychopathology [see comments]. Can J Psychiatry 45: 247-256.

Cloninger CR (1986). A unified biosocial theory of personality and its role in the development of anxiety states. Psychiatr Dev 4: $167-226$.

Cloninger CR (1987). A systematic method for clinical description and classification of personality variants. Arch Gen Psychiatry 44: $573-588$.

Cohen JD, Braver TS, Brown JW (2002). Computational perspectives on dopamine function in prefrontal cortex [Review] [76 refs]. Curr Opin Neurobiol 12: 223-229.

Comings DE (2001). Clinical and molecular genetics of ADHD and Tourette syndrome. Two related polygenic disorders. Ann NY Acad Sci 931: 50-83.

Comings DE, Gade-Andavolu R, Gonzalez N, Wu S, Muhleman D, Blake $\mathrm{H}$ et al (2000). Multivariate analysis of associations of 42 genes in ADHD, ODD and conduct disorder. Clin Genet 58: 31-40.

Cornblatt BA, Lencz T, Kane JM (2001). Treatment of the schizophrenia prodrome: is it presently ethical? Schizophr Res 51: $31-38$

Daniel DG, Berman KF, Weinberger DR (1989). The effect of apomorphine on regional cerebral blood flow in schizophrenia. J Neuropsychiatry 1: 377-384.

Diamond A, Briand L, Fossella J, Gehlbach L (2004). Genetic and neurochemical modulation of prefrontal cognitive functions in children. Am J Psychiatry 161: 125-132.

Douglas RJ, Pribram KH (1969). Distraction and habituation in monkeys with limbic lesions. J Comp Physiol Psychol 69: 473-480.

Durstewitz D, Kelc M, Gunturkun O (1999). A neurocomputational theory of the dopaminergic modulation of working memory functions. J Neurosci 19: 2807-2822.

Durstewitz D, Seamans JK (2002). The computational role of dopamine D1 receptors in working memory. Neural Networks 15: 572.

Durstewitz D, Seamans JK, Sejnowski TJ (2000a). Dopamine-mediated stabilization of delay-period activity in a network model of prefrontal cortex. J Neurophysiol 83: $1733-1750$.

Durstewitz D, Seamans JK, Sejnowski TJ (2000b). Neurocomputational models of working memory [Review] [77 refs]. Nat Neurosci 3(Suppl): 1184-1191.

Egan MF, Goldberg TE, Gscheidle T, Weirich M, Bigelow LB, Weinberger DR (2000). Relative risk of attention deficits in siblings of patients with schizophrenia. Am J Psychiatry 157: 1309-1316.

Egan MF, Goldberg TE, Kolachana BS, Callicott JH, Mazzanti CM, Straub RE et al (2001). Effect of COMT Val108/158 Met genotype on frontal lobe function and risk for schizophrenia. Proc Natl Acad Sci USA 98: 6917-6922.

Eisenberg J, Mei-Tal G, Steinberg A, Tartakovsky E, Zohar A, Gritsenko I et al (1999). Haplotype relative risk study of catechol-O-methyltransferase (COMT) and attention deficit hyperactivity disorder (ADHD): association of the high-enzyme activity Val allele with ADHD impulsive-hyperactive phenotype. Am J Med Genet 88: 497-502.

Enoch MA, Xu K, Ferro E, Harris CR, Goldman D (2003). Genetic origins of anxiety in women: a role for a functional catechol-O-methyltransferase polymorphism. Psychiatr Genet 13: $33-41$

Fan J, McCandliss BD, Sommer T, Raz A, Posner MI (2002). Testing the efficiency and independence of attentional networks. J Cogn Neurosci 14: 340-347. 
Fernandes C, Paya-Cano JL, Sluyter F, D’Souza U, Plomin R, Schalkwyk LC (2004). Hippocampal gene expression profiling across eight mouse inbred strains: towards understanding the molecular basis for behaviour. Eur J Neurosci 19: 2576-2582.

Fiorillo CD, Tobler PN, Schultz W (2003). Discrete coding of reward probability and uncertainty by dopamine neurons. Science 299: 1898-1902.

Fletcher PC, Henson RN (2001). Frontal lobes and human memory: insights from functional neuroimaging. Brain 124: 849-881.

Floresco SB, West AR, Ash B, Moore H, Grace AA (2003). Afferent modulation of dopamine neuron firing differentially regulates tonic and phasic dopamine transmission. Nat Neurosci 6: $968-$ 973.

Floresco SB, West AR, Grace AA (2004). Reply to 'extrasynaptic dopamine and phasic neuronal activity'. Nat Neurosci 7: 199.

Fuster JM (1999). Synopsis of function and dysfunction of the frontal lobe. Acta Psychiatr Scand Suppl 395: 51-57.

Gasparini M, Fabrizio E, Bonifati V, Meco G (1997). Cognitive improvement during tolcapone treatment in Parkinson's disease. J Neural Transm 104: 887-894.

Giller Jr EL, Young JG, Breakefield XO, Carbonari C, Braverman M, Cohen DJ (1980). Monoamine oxidase and catechol- $O$ methyltransferase activities in cultured fibroblasts and blood cells from children with autism and the Gilles de la Tourette syndrome. Psychiatry Res 2: 187-197.

Glatt SJ, Faraone SV, Tsuang MT (2003). Association between a functional catechol $O$-methyltransferase gene polymorphism and schizophrenia: meta-analysis of case-control and family-based studies. Am J Psychiatry 160: 469-476.

Gogos JA, Morgan M, Luine V, Santha M, Ogawa S, Pfaff D et al (1998). Catechol-O-methyltransferase-deficient mice exhibit sexually dimorphic changes in catecholamine levels and behavior. Proc Natl Acad Sci USA 95: 9991-9996.

Goldberg E, Bilder RM (1987). The frontal lobes and hierarchical organization of cognitive control. In: Perecman E (ed). The Frontal Lobes Revisited. IRBN Press: New York. pp 159-187.

Goldberg TE, Bigelow LB, Weinberger DR, Daniel DG, Kleinman JE (1991). Cognitive and behavioral effects of the coadministration of dextroamphetamine and haloperidol in schizophrenia. $\mathrm{Am}$ Psychiatry 148: 78-84.

Goldberg TE, Egan MF, Gscheidle T, Coppola R, Weickert T, Kolachana BS et al (2003). Executive subprocesses in working memory: relationship to catechol-O-methyltransferase $\mathrm{Val}^{158} \mathrm{Met}$ genotype and schizophrenia. Arch Gen Psychiatry 60: 889-896.

Goldman-Rakic PS (1995a). Architecture of the prefrontal cortex and the central executive [Review] [37 refs]. Ann NY Acad Sci 769: 71-83.

Goldman-Rakic PS (1995b). Cellular basis of working memory [Review] [64 refs]. Neuron 14: 477-485.

Goldman-Rakic PS (1998). The cortical dopamine system: role in memory and cognition [Review] [14 refs]. Adv Pharmacol 42: 707-711.

Gorelova N, Seamans JK, Yang CR (2002). Mechanisms of dopamine activation of fast-spiking interneurons that exert inhibition in rat prefrontal cortex. J Neurophysiol 88: 3150-3166.

Grace AA (1991). Phasic versus tonic dopamine release and the modulation of dopamine system responsivity: a hypothesis for the etiology of schizophrenia. Neuroscience 41: 1-24.

Grace AA (1993). Cortical regulation of subcortical dopamine systems and its possible relevance to schizophrenia. J Neural Transm Gen Sect 91: 111-134.

Grace AA (2000). The tonic/phasic model of dopamine system regulation and its implications for understanding alcohol and psychostimulant craving [Review] [66 refs]. Addiction 95(Suppl 2): $\mathrm{S} 119-\mathrm{S} 128$

Gray JA (1978). The neuropsychology of anxiety. Br J Psychol 69: 417-434.
Gray JA (1982). Precis of the neuropsychology of anxiety: an enquiry into the functions of the septo-hippocampal system. Behav Brain Sci 5: 469-534.

Gray JA (1983). A theory of anxiety: the role of the limbic system. Encephale 9: 161B-166B.

Gray JA (1985). The neuropsychology of anxiety. Issues Ment Health Nurs 7: 201-228.

Gray JA (1988). Behavioural and neural-system analyses of the actions of anxiolytic drugs. Pharmacol Biochem Behav 29: 767-769.

Gray JA, McNaughton N (1996). The neuropsychology of anxiety: reprise [Review] [175 refs]. Nebr Symp Motiv 43: 61-134.

Gresch PJ, Sved AF, Zigmond MJ, Finlay JM (1995). Local influence of endogenous norepinephrine on extracellular dopamine in rat medial prefrontal cortex. J Neurochem 65: 111-116.

Grossberg S (1999). Neural models of normal and abnormal behavior: what do schizophrenia, parkinsonism, attention deficit disorder, and depression have in common? Prog Brain Res 121: 375-406.

Gunduz H, Zuffante P, Wu H, Crandall D, Szeszko P, Alvir J et al (1999). Longitudinal follow-up of superior temporal gyrus gray matter in first-episode schizophrenia. Schizophr Res 36: 199.

Halgren E, Boujon C, Clarke J, Wang C, Chauvel P (2002). Rapid distributed fronto-parieto-occipital processing stages during working memory in humans. Cereb Cortex 12: 710-728.

Hallikainen T, Lachman H, Saito T, Volavka J, Kauhanen J, Salonen JT et al (2000). Lack of association between the functional variant of the catechol- $O$-methyltransferase (COMT) gene and early-onset alcoholism associated with severe antisocial behavior. Am J Med Genet 96: 348-352.

Hallikainen T, Saito T, Lachman HM, Volavka J, Pohjalainen T, Ryynanen OP et al (1999). Association between low activity serotonin transporter promoter genotype and early onset alcoholism with habitual impulsive violent behavior. Mol Psychiatry 4: 385-388.

Hawi Z, Millar N, Daly G, Fitzgerald M, Gill M (2000). No association between catechol-O-methyltransferase (COMT) gene polymorphism and attention deficit hyperactivity disorder (ADHD) in an Irish sample. Am J Med Genet 96: 282-284.

Herken H, Erdal ME (2001). Catechol-O-methyltransferase gene polymorphism in schizophrenia: evidence for association between symptomatology and prognosis. Psychiatric Genet 11: 105-109.

Hoffman RE (1992). Attractor neural networks and psychotic disorders. Psychiatric Ann 22: 3.

Huotari M, Gogos JA, Karayiorgou M, Koponen O, Forsberg M, Raasmaja A et al (2002). Brain catecholamine metabolism in catechol-O-methyltransferase (COMT)-deficient mice. Eur J Neurosci 15: 246-256.

Ichikawa J, Ishii $\mathrm{H}$, Bonaccorso $\mathrm{S}$, Fowler WL, O'Laughlin IA, Meltzer HY (2001). 5-HT(2A) and $\mathrm{D}(2)$ receptor blockade increases cortical DA release via $5-\mathrm{HT}(1 \mathrm{~A})$ receptor activation: a possible mechanism of atypical antipsychotic-induced cortical dopamine release. J Neurochem 76: 1521-1531.

Illi A, Kampman O, Anttila S, Roivas M, Mattila KM, Lehtimaki T et al (2003a). Interaction between angiotensin-converting enzyme and catechol-O-methyltransferase genotypes in schizophrenics with poor response to conventional neuroleptics. Eur Neuropsychopharmacol 13: 147-151.

Illi A, Mattila KM, Kampman O, Anttila S, Roivas M, Lehtimaki T et al (2003b). Catechol- $O$-methyltransferase and monoamine oxidase A genotypes and drug response to conventional neuroleptics in schizophrenia. J Clin Psychopharmacol 23: 429-434.

Inada T, Nakamura A, Iijima Y (2003). Relationship between catechol-O-methyltransferase polymorphism and treatment-resistant schizophrenia. Am J Med Genet 120B: 35-39. 
Ishiguro H, Haruo ST, Toru M, Saito T, Arinami T (1999). Association study between high and low activity polymorphism of catechol-O-methyltransferase gene and alcoholism. Psychiatric Genet 9: 135-138.

Jaskiw GE, Karoum FK, Weinberger DR (1990). Persistent elevations in dopamine and its metabolites in the nucleus accumbens after mild subchronic stress in rats with ibotenic acid lesions of the medial prefrontal cortex. Brain Res 534: 321-323.

Jones G, Zammit S, Norton N, Hamshere ML, Jones SJ, Milham C et al (2001). Aggressive behaviour in patients with schizophrenia is associated with catechol-O-methyltransferase genotype. $\mathrm{Br} J$ Psychiatry 179: 351-355.

Joober R, Gauthier J, Lal S, Bloom D, Lalonde P, Rouleau G et al (2002). Catechol-O-methyltransferase Val-108/158-Met gene variants associated with performance on the Wisconsin Card Sorting Test. Arch Gen Psychiatry 59: 662-663.

Karayiorgou M, Altemus M, Galke BL, Goldman D, Murphy DL, Ott J et al (1997). Genotype determining low catechol-Omethyltransferase activity as a risk factor for obsessivecompulsive disorder. Proc Natl Acad Sci USA 94: 4572-4575.

Karayiorgou M, Sobin C, Blundell ML, Galke BL, Malinova L, Goldberg P et al (1999). Family-based association studies support a sexually dimorphic effect of COMT and MAOA on genetic susceptibility to obsessive-compulsive disorder. Biol Psychiatry 45: 1178-1189.

Kauhanen J, Hallikainen T, Tuomainen TP, Koulu M, Karvonen MK, Salonen JT et al (2000). Association between the functional polymorphism of catechol- $O$-methyltransferase gene and alcohol consumption among social drinkers. Alcoholism: Clin Exp Res 24: 135-139.

Khromova I, Rauhala P, Zolotov N, Mannisto PT (1995). Tolcapone, an inhibitor of catechol $O$-methyltransferase, counteracts memory deficits caused by bilateral cholinotoxin lesions of the basal nuclei of Meynert. NeuroReport 6: 1219-1222.

Khromova I, Voronina T, Kraineva VA, Zolotov N, Mannisto PT (1997). Effects of selective catechol-O-methyltransferase inhibitors on single-trial passive avoidance retention in male rats. Behav Brain Res 86: 49-57.

Kirley A, Hawi Z, Daly G, McCarron M, Mullins C, Millar N et al (2002a). Dopaminergic system genes in ADHD: toward a biological hypothesis. Neuropsychopharmacology 27: 607-619.

Kirley A, Hawi Z, Daly G, McCarron M, Mullins C, Millar N et al (2002b). Dopaminergic system genes in ADHD: toward a biological hypothesis. Neuropsychopharmacology 27: 607-619.

Kopin IJ (1985). Catecholamine metabolism: basic aspects and clinical significance. Pharmacol Rev 37: 333-364.

Kotler M, Barak P, Cohen H, Averbuch IE, Grinshpoon A, Gritsenko I et al (1999). Homicidal behavior in schizophrenia associated with a genetic polymorphism determining low catechol $\mathrm{O}$-methyltransferase (COMT) activity. Am J Med Genet 88: 628-633.

Kusak G, Grune K, Hagendorf H, Metz AM (2000). Updating of working memory in a running memory task: an event-related potential study. Int J Psychophysiol 39: 51-65.

Lachman HM, Nolan KA, Mohr P, Saito T, Volavka J (1998). Association between catechol $O$-methyltransferase genotype and violence in schizophrenia and schizoaffective disorder. Am J Psychiatry 155: 835-837.

Lachman HM, Papolos DF, Saito T, Yu YM, Szumlanski CL, Weinshilboum RM (1996). Human catechol-O-methyltransferase pharmacogenetics: description of a functional polymorphism and its potential application to neuropsychiatric disorders. Pharmacogenetics 6: 243-250.

Lake CR, Ziegler MG, Eldridge R, Murphy DL (1977). Catecholamine metabolism in Gilles de la Tourette's syndrome. Am J Psychiatry 134: 257-260.
Lammers AJ, Van Rossum JM (1968). Bizarre social behaviour in rats induced by a combination of a peripheral decarboxylase inhibitor and DOPA. Eur J Pharmacol 5: 103-106.

Laruelle M, Abi-Dargham A (1999). Dopamine as the wind of the psychotic fire: new evidence from brain imaging studies. J Psychopharmacol 13: 358-371.

Lencz T, Bilder RM, Cornblatt B (2001a). The timing of neurodevelopmental abnormality in schizophrenia: an integrative review of the neuroimaging literature. CNS Spectrums 6: 233-255.

Lencz T, Cornblatt B, Bilder RM (2001b). Neurodevelopmental models of schizophrenia: pathophysiologic synthesis and directions for intervention research. Psychopharmacol Bull 35: 95-125.

Levy DL, Smith M, Robinson D, Jody D, Lerner G, Alvir J et al (1993). Methylphenidate increases thought disorder in recent onset schizophrenics, but not in normal controls. Biol Psychiatry 34: 507-514.

Lewis BL, O'Donnell P (2000). Ventral tegmental area afferents to the prefrontal cortex maintain membrane potential 'up' states in pyramidal neurons via $\mathrm{D}(1)$ dopamine receptors. Cereb Cortex 10: $1168-1175$.

Lewis DA, Melchitzky DS, Sesack SR, Whitehead RE, Auh S, Sampson A (2001). Dopamine transporter immunoreactivity in monkey cerebral cortex: regional, laminar, and ultrastructural localization. J Comp Neurol 432: 119-136.

Li T, Sham PC, Vallada H, Xie T, Tang X, Murray RM et al (1996). Preferential transmission of the high activity allele of COMT in schizophrenia. Psychiatric Genet 6: 131-133.

Lieberman JA, Kane JM, Gadaleta D, Brenner R, Lesser MS, Kinon B (1984). Methylphenidate challenge as a predictor of relapse in schizophrenia. Am J Psychiatry 141: 633-638.

Liljequist R, Haapalinna A, Ahlander M, Li YH, Mannisto PT (1997). Catechol $O$-methyltransferase inhibitor tolcapone has minor influence on performance in experimental memory models in rats. Behav Brain Res 82: 195-202.

Luria AR (1980). Higher Cortical Functions in Man. Basic Books: New York.

Lyon M, Robbins TW (1975). The action of central nervous system stimulant drugs: a general theory concerning amphetamine effects. In: Essman W, Valzelli L (eds). Current Developments in Psychopharmacology, Vol. 2. Spectrum: New York. pp 79-163.

Malhotra AK, Kestler LJ, Mazzanti C, Bates JA, Goldberg T, Goldman D (2002). A functional polymorphism in the COMT gene and performance on a test of prefrontal cognition. Am J Psychiatry 159: 652-654.

Manor I, Kotler M, Sever Y, Eisenberg J, Cohen H, Ebstein RP et al (2000). Failure to replicate an association between the catechol$O$-methyltransferase polymorphism and attention deficit hyperactivity disorder in a second, independently recruited Israeli cohort. Am J Med Genet 96: 858-860.

Mattay VS, Goldberg TE, Fera F, Hariri AR, Tessitore A, Egan MF et al (2003). Catechol $O$-methyltransferase val158-met genotype and individual variation in the brain response to amphetamine. Proc Natl Acad Sci USA 100: 6186-6191.

McDougle CJ, Goodman WK, Leckman JF, Lee NC, Heninger GR, Price LH (1994a). Haloperidol addition in fluvoxamine-refractory obsessive-compulsive disorder. A double-blind, placebocontrolled study in patients with and without tics. Arch Gen Psychiatry 51: 302-308.

McDougle CJ, Goodman WK, Price LH (1994b). Dopamine antagonists in tic-related and psychotic spectrum obsessivecompulsive disorder. J Clin Psychiatry 55(Suppl): 24-31.

McDougle CJ, Goodman WK, Price LH, Delgado PL, Krystal JH, Charney DS et al (1990). Neuroleptic addition in fluvoxaminerefractory obsessive-compulsive disorder. Am J Psychiatry 147: 652-654. 
McGuinness D, Pribram K (1980). The neuropsychology of attention: emotional and motivational controls. In: Wittrock MC (ed). The Brain and Psychology. Academic Press: New York. pp 95-139.

McNaughton N, Gray JA (2000). Anxiolytic action on the behavioural inhibition system implies multiple types of arousal contribute to anxiety. J Affect Disord 61: 161-176.

Meltzer HY, Li Z, Kaneda Y, Ichikawa J (2003). Serotonin receptors: their key role in drugs to treat schizophrenia. Prog Neuropsychopharmacol Biol Psychiatry 27: 1159-1172.

Menon V, Mackenzie K, Rivera SM, Reiss AL (2002). Prefrontal cortex involvement in processing incorrect arithmetic equations: evidence from event-related fMRI. Hum Brain Mapping 16: 119-130.

Moghaddam B, Berridge CW, Goldman-Rakic PS, Bunney BS, Roth $\mathrm{RH}$ (1993). In vivo assessment of basal and drug-induced dopamine release in cortical and subcortical regions of the anesthetized primate. Synapse 13: 215-222.

Monchi O, Petrides M, Petre V, Worsley K, Dagher A (2001). Wisconsin Card Sorting revisited: distinct neural circuits participating in different stages of the task identified by eventrelated functional magnetic resonance imaging. J Neurosci 21: 7733-7741.

Moore H, West AR, Grace AA (1999). The regulation of forebrain dopamine transmission: relevance to the pathophysiology and psychopathology of schizophrenia [Review] [170 refs]. Biol Psychiatry 46: 40-55.

Niehaus DJ, Kinnear CJ, Corfield VA, du Toit PL, van Kradenburg J, Moolman-Smook JC et al (2001). Association between a catechol-O-methyltransferase polymorphism and obsessivecompulsive disorder in the Afrikaner population. J Affect Disord 65: 61-65.

Nolan KA, Bilder RM, Lachman HM, Volavka J (2004). Catechol Omethyltransferase val(158)met polymorphism in schizophrenia: differential effects of val and met alleles on cognitive stability and flexibility. Am J Psychiatry 161: 359-361.

Nolan KA, Czobor P, Roy BB, Platt MM, Shope CB, Citrome LL et al (2003). Characteristics of assaultive behavior among psychiatric inpatients. Psychiatr Serv 54: 1012-1016.

Ohara K, Nagai M, Suzuki Y, Ochiai M, Ohara K (1998). No association between anxiety disorders and catechol-O-methyltransferase polymorphism. Psychiatry Res 80: 145-148.

Ohmori O, Shinkai T, Kojima H, Terao T, Suzuki T, Mita T et al (1998). Association study of a functional catechol-O-methyltransferase gene polymorphism in Japanese schizophrenics. Neurosci Lett 243: 109-112.

Overall JE, Gorham DR (1962). The Brief Psychiatric Rating Scale. Psychol Rep 10: 799-812.

Palmatier MA, Kang AM, Kidd KK (1999). Global variation in the frequencies of functionally different catechol-O-methyltransferase alleles. Biol Psychiatry 46: 557-567.

Papolos DF, Veit S, Faedda GL, Saito T, Lachman HM (1998). Ultra-ultra rapid cycling bipolar disorder is associated with the low activity catecholamine-O-methyltransferase allele. $\mathrm{Mol}$ Psychiatry 3: 346-349.

Parsons LH, Justice Jr JB (1992). Extracellular concentration and in vivo recovery of dopamine in the nucleus accumbens using microdialysis. J Neurochem 58: 212-218.

Pauls DL, Alsobrook JP (1999). The inheritance of obsessivecompulsive disorder. Child Adolesc Psychiatr Clin N Am 8: 481-496 viii.

Paulus MP, Bilder RM, Lieberman JA (1999). Complex dysregulation in sequential organization and dysregulation in dopaminergic modulation in first episode schizophrenia patients. In: Prahdan N, Rapp PE, Sreenivasan R (eds). Nonlinear Dynamics and Brain Functioning. Nova: Huntington, NY.

Paulus MP, Callaway CW, Geyer MA (1993). Quantitative assessment of the microstructure of rat behavior: II Distinctive effects of dopamine releasers and uptake inhibitors. Psychopharmacology 113: 187-198.

Paulus MP, Geyer MA, Braff DL (1996). Use of methods from chaos theory to quantify a fundamental dysfunction in the behavioral organization of schizophrenic patients. Am J Psychiatry 153: 714-717.

Paulus MP, Geyer MA, Braff DL (1994). The assessment of sequential response organization in schizophrenic and control subjects. Prog Neuropsychopharmacol Biol Psychiatry 18: 1169-1185.

Payton A, Holmes J, Barrett JH, Hever T, Fitzpatrick H, Trumper $\mathrm{AL}$ et al (2001). Examining for association between candidate gene polymorphisms in the dopamine pathway and attentiondeficit hyperactivity disorder: a family-based study. $A m \mathrm{~J} \mathrm{Med}$ Genet 105: 464-470.

Peeters M, Maloteaux JM, Hermans E (2003). Distinct effects of amantadine and memantine on dopaminergic transmission in the rat striatum. Neurosci Lett 343: 205-209.

Petrides M, Alivisatos B, Frey S (2002). Differential activation of the human orbital, mid-ventrolateral, and mid-dorsolateral prefrontal cortex during the processing of visual stimuli. Proc Natl Acad Sci USA 99: 5649-5654.

Pribram KH (1987). The subdivisions of the frontal cortex revisited. In Perecman E (ed) The Frontal Lobes Revisited. IRBN Press: New York. pp 11-39.

Pribram KH, McGuinness D (1975). Arousal, activation, and effort in the control of attention. Psychol Rev 82: 116-149.

Pycock CJ, Kerwin RW, Carter CJ (1980). Effect of lesion of cortical dopamine terminals on subcortical dopamine receptors in rats. Nature 286: 74-76.

Qian Q, Wang Y, Zhou R, Li J, Wang B, Glatt S et al (2003). Familybased and case-control association studies of catechol-Omethyltransferase in attention deficit hyperactivity disorder suggest genetic sexual dimorphism. Am J Med Genet 118B: 103-109.

Radvansky GAC (2001). Working memory and situation model updating. Memory Cogn 29: 1073-1080.

Rotondo A, Mazzanti C, Dell'Osso L, Rucci P, Sullivan P, Bouanani $S$ et al (2002). Catechol $O$-methyltransferase, serotonin transporter, and tryptophan hydroxylase gene polymorphisms in bipolar disorder patients with and without comorbid panic disorder. Am J Psychiatry 159: 23-29.

Rujescu D, Giegling I, Gietl A, Hartmann AM, Moller HJ (2003). A functional single nucleotide polymorphism $\left(\mathrm{V}^{158} \mathrm{M}\right)$ in the COMT gene is associated with aggressive personality traits. Biol Psychiatry 54: 34-39.

Schindler KM, Richter MA, Kennedy JL, Pato MT, Pato CN (2000). Association between homozygosity at the COMT gene locus and obsessive-compulsive disorder. Am J Med Genet 96: 721-724.

Schultz W (2002). Getting formal with dopamine and reward. Neuron 36: 241-263.

Schultz W, Tremblay L, Hollerman JR (2003). Changes in behavior-related neuronal activity in the striatum during learning. Trends Neurosci 26: 321-328.

Seamans JK, Gorelova N, Durstewitz D, Yang CR (2001). Bidirectional dopamine modulation of GABAergic inhibition in prefrontal cortical pyramidal neurons. J Neurosci 21: 3628-3638.

Senault B (1970). Comportement d'aggresivité intraspécifique induit par l'apomorphine chez la rat. Psychopharmacologia 18: 271-287.

Sesack SR, Hawrylak VA, Matus C, Guido MA, Levey AI (1998). Dopamine axon varicosities in the prelimbic division of the rat prefrontal cortex exhibit sparse immunoreactivity for the dopamine transporter. J Neurosci 18: 2697-2708.

Shapiro AK, Baron M, Shapiro E, Levitt M (1984). Enzyme activity in Tourette's syndrome. Arch Neurol 41: 282-285. 
Sharp T, Zetterstrom T, Ungerstedt U (1986). An in vivo study of dopamine release and metabolism in rat brain regions using intracerebral dialysis. J Neurochem 47: 113-122.

Shifman S, Bronstein M, Sternfeld M, Pisante-Shalom A, Lev-Lehman E, Weizman A et al (2002). A highly significant association between a COMT haplotype and schizophrenia. Am J Hum Genet 71: 1296-1302.

Smiley JF, Levey AI, Ciliax BJ, Goldman-Rakic PS (1994). D1 dopamine receptor immunoreactivity in human and monkey cerebral cortex: predominant and extrasynaptic localization in dendritic spines. Proc Natl Acad Sci USA 91: 5720-5724.

Sonuga-Barke EJ (2003). The dual pathway model of AD/HD: an elaboration of neuro-developmental characteristics. Neurosci Biobehav Rev 27: 593-604.

Stahl SM (2001a). Dopamine system stabilizers, aripiprazole, and the next generation of antipsychotics, part 1, 'Goldilocks' actions at dopamine receptors. J Clin Psychiatry 62: 841-842.

Stahl SM (2001b). Dopamine system stabilizers, aripiprazole, and the next generation of antipsychotics, part 2: illustrating their mechanism of action. J Clin Psychiatry 62: 923-924.

Strous RD, Bark N, Parsia SS, Volavka J, Lachman HM (1997). Analysis of a functional catechol-O-methyltransferase gene polymorphism in schizophrenia: evidence for association with aggressive and antisocial behavior. Psychiatry Res 69: 71-77.

Strous RD, Nolan KA, Lapidus R, Diaz L, Saito T, Lachman HM (2003). Aggressive behavior in schizophrenia is associated with the low enzyme activity COMT polymorphism: a replication study. Am J Med Genet 120B: 29-34.

Szeszko PR, Robinson D, Alvir JM, Bilder RM, Lencz T, Ashtari M et al (1999). Orbital frontal and amygdala volume reductions in obsessive-compulsive disorder. Arch Gen Psychiatry 56: 913-919.

Tahir E, Curran S, Yazgan Y, Ozbay F, Cirakoglu B, Asherson PJ (2000). No association between low- and high-activity catecholamine-methyl-transferase (COMT) and attention deficit hyperactivity disorder (ADHD) in a sample of Turkish children. Am J Med Genet 96: 285-288.
Tiihonen J, Hallikainen T, Lachman H, Saito T, Volavka J, Kauhanen J et al (1999). Association between the functional variant of the catechol-O-methyltransferase (COMT) gene and type 1 alcoholism. Molecular Psychiatry 4: 286-289.

Tsai SJ, Yu YW, Chen TJ, Chen JY, Liou YJ, Chen MC et al (2003). Association study of a functional catechol-O-methyltransferasegene polymorphism and cognitive function in healthy females. Neurosci Lett 338: 123-126.

Volavka J (2002). Risk for individuals with schizophrenia who are living in the community. Psychiatr Serv 53: 484-485.

Volavka J, Kennedy JL, Ni X, Czobor P, Nolan K, Sheitman B et al (2004). COMT158 polymorphism and hostility. Am J Med Genet 127B: $28-29$.

Volkow ND, Swanson JM (2003). Variables that affect the clinical use and abuse of methylphenidate in the treatment of ADHD. Am J Psychiatry 160: 1909-1918.

Wang T, Franke P, Neidt H, Cichon S, Knapp M, Lichtermann D et al (2001). Association study of the low-activity allele of catechol-O-methyltransferase and alcoholism using a familybased approach. Mol Psychiatry 6: 109-111.

Weinberger DR, Egan MF, Bertolino A, Callicott JH, Mattay VS, Lipska BK et al (2001). Prefrontal neurons and the genetics of schizophrenia. Biol Psychiatry 50: 825-844.

Weinshilboum RM, Otterness DM, Szumlanski CL (1999). Methylation pharmacogenetics: catechol $O$-methyltransferase, thiopurine methyltransferase, and histamine $\mathrm{N}$-methyltransferase [Review] [157 refs]. Annu Rev Pharmacol Toxicol 39: 19-52.

West AR, Moore H, Grace AA (2002). Direct examination of local regulation of membrane activity in striatal and prefrontal cortical neurons ' using simultaneous intracellular recording and microdialysis. J Pharmacol Exp Ther 301: 867-877.

Yamamoto BK, Novotney S (1998). Regulation of extracellular dopamine by the norepinephrine transporter. J Neurochem 71: 274-280.

Zhang XN, Ruan LM, Le YP, Zhang Y (2003). Association analysis between attention-deficit hyperactivity disorder and $\mathrm{Val}^{158} \mathrm{Met}$ polymorphism of catechol-O-methyltransferase gene. Zhonghua Yi Xue Za Zhi 20: 322-324. 